Annales Geophysicae (2003) 21: 583-596 (c) European Geosciences Union 2003

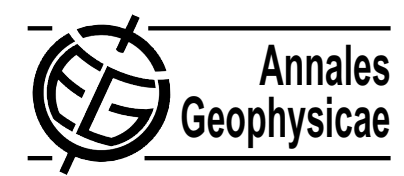

\title{
Geomagnetic storm effects at F1-layer heights from incoherent scatter observations
}

\author{
A. V. Mikhailov ${ }^{1}$ and K. Schlegel ${ }^{2}$ \\ ${ }^{1}$ Institute of Terrestrial Magnetism, Ionosphere and Radio Wave Propagation, Troitsk, Moscow Region 142190, Russia \\ ${ }^{2}$ Max-Planck-Institute für Aeronomie, Max-Planck-Str. 2, D-37191 Katlenburg-Lindau, Germany
}

Received: 18 April 2002 - Revised: 24 July 2002 - Accepted: 30 August 2002

\begin{abstract}
Storm effects at F1-layer heights (160-200 km) were analyzed for the first time using Millstone Hill (midlatitudes) and EISCAT (auroral zone) incoherent scatter (IS) observations. The morphological study has shown both increases (positive effect) and decreases (negative effect) in electron concentration. Negative storm effects prevail for all seasons and show a larger magnitude than positive ones, the magnitude of the effect normally increasing with height. At Millstone Hill the summer storm effects are small compared to other seasons, but they are well detectable. At EISCAT this summer decrease takes place only with respect to the autumnal period and the autumn/spring asymmetry in the storm effects is well pronounced. Direct and significant correlation exists between deviations in electron concentration at the F1-layer heights and in the F2-layer maximum. Unlike the F2-layer the F1-region demonstrates a relatively small reaction to geomagnetic disturbances despite large perturbations in thermospheric parameters. Aeronomic parameters extracted from IS observations are used to explain the revealed morphology. A competition between atomic and molecular ion contributions to $N e$ variations was found to be the main physical mechanism controlling the F1-layer storm effect. The revealed morphology is shown to be related with neutral composition $\left(\mathrm{O}, \mathrm{O}_{2}, \mathrm{~N}_{2}\right)$ seasonal and storm-time variations. The present day understanding of the F1-region formation mechanisms is sufficient to explain the observed storm effects.
\end{abstract}

Key words. Atmospheric composition and structure (thermosphere-composition and chemistry); ionosphere (ion chemistry and composition; ionospheric disturbances)

\section{Introduction}

Ionospheric disturbances related to geomagnetic storms are widely discussed in literature (see the reviews by Prölss,

Correspondence to: K. Schlegel

(schlegel@linmpi.mpg.de)
1995; Buonsanto, 1999; Mikhailov, 2000; Richmond, 2000; Danilov and Lastovicka, 2001 and references therein). The main attention is paid to the F2-layer storm effects being the most pronounced and impressive, while F1-layer disturbances are practically not discussed. On the one hand, this is due to the problems with the $f o F 1$ identification (Shchepkin and Vinitzky, 1981); on the other hand, F1-layer storm effects are relatively small compared to the F2-layer ones and are not very important from the radio-wave propagation point of view. Theory of the F1-layer formation (Shchepkin, 1969; Shchepkin et al., 1972; Antonova and Ivanov-Kholodny, 1988a, b) indicates a close relationship between F1-layer electron concentration and neutral composition. Therefore, the observed small reaction of the F1-region to the geomagnetic disturbances followed by large perturbations in the thermospheric parameters is interesting from a physical point of view and should be explained. Recently, Buresova and Lastovicka (2001), and Buresova et al. (2002) have attempted to systematize the F1-layer storm effects analyzing $N e(\mathrm{~h})$ profiles obtained from the ionogram reduction over some $\mathrm{Eu}-$ ropean ionosonde stations. The analysis revealed two interesting effects: (i) independently of the sign of the F2layer disturbance (positive or negative), the F1-layer electron concentration always decreases (negative storm effect), (ii) there exists a summer/winter and autumn/spring asymmetry in the F1-layer geomagnetic storm effects. They have shown that the summer F1-layer (the electron concentration at $160-190 \mathrm{~km}$ ) practically does not react to geomagnetic storms, while a well detectable negative storm effect takes place in winter, and also, that autumnal storm effects are stronger than vernal ones. These conclusions need further analysis to check whether such an F1-layer reaction is systematic or the results just reflect the peculiarity of the observations chosen. Electron concentration both in the F2and F1-regions is known to be strongly dependent on neutral composition as the processes of photoionization and recombination are mainly the same. So, in principle, one may expect a synchronous (to some extent) type of $N m \mathrm{~F} 2$ and $\mathrm{Ne} \mathrm{F} 1$ storm variations. The results by Vinitzky et al. (1982) 

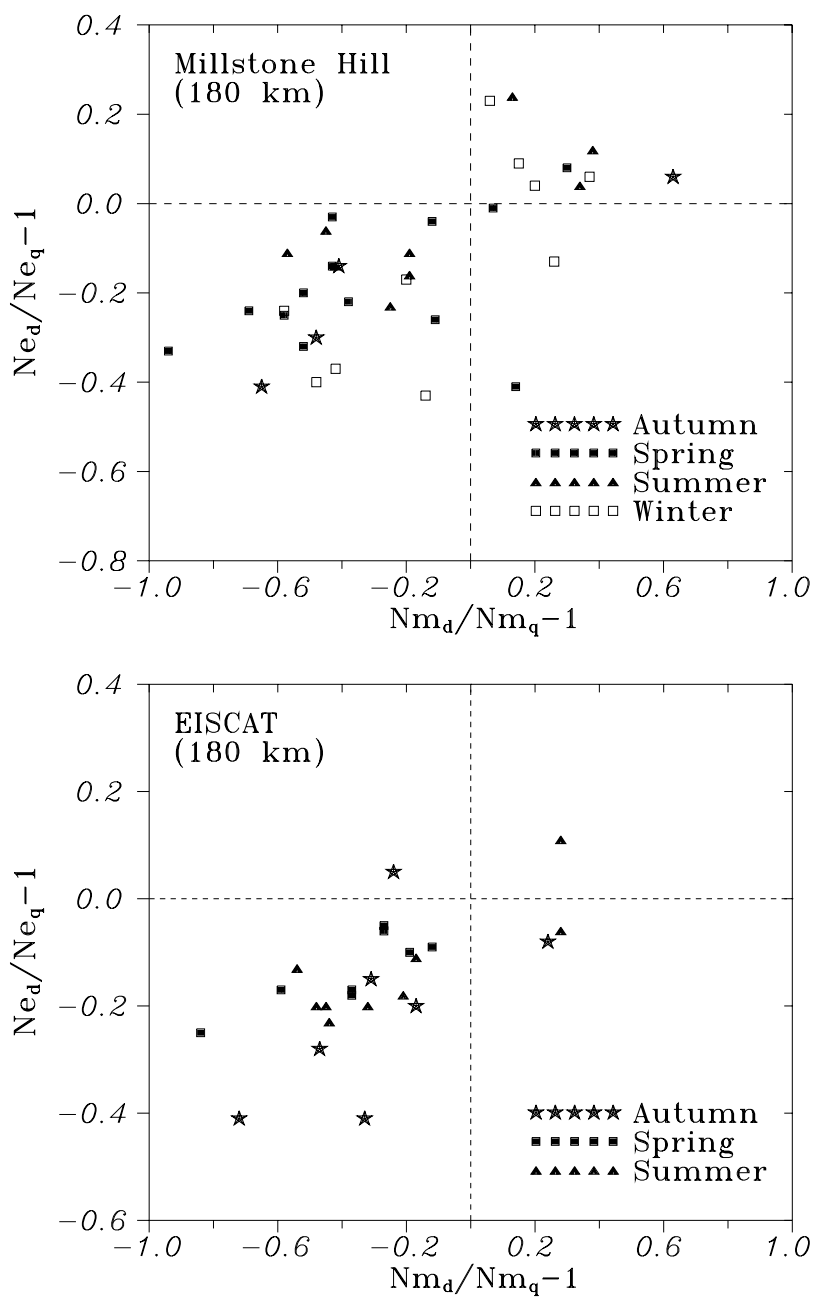

Fig. 1. The relative (disturbed/quiet) deviations $\delta N e$ at $180 \mathrm{~km}$ versus relative deviations $\delta N m \mathrm{~F} 2$ for Millstone Hill and EISCAT storm observations.

seem to confirm this. With respect to the sign of the F1-layer storm effect, the ionogram reduction for Moscow (Zevakina et al., 1971) yielded in some cases positive $\Delta N e$ at F1-layer heights during daytime hours. Therefore, the aim of the paper is to analyze the effects of geomagnetic disturbances at F1-layer heights (160-200 km) using Millstone Hill (middle latitudes) and EISCAT (auroral zone) incoherent scatter (IS) daytime observations, and to give a physical interpretation to the revealed $N e(\mathrm{~h})$ variations.

\section{Observations}

All available Millstone Hill (zenith observations) and EISCAT CP-1 and CP-2 (field-aligned multi-pulse, as well as long-pulse) observations were examined to select couples (disturbed/reference) of days with daytime observations. We have tried to choose reference days to be geomagnetically quiet and close in time to the analyzed disturbed ones, but this was impossible in some cases due to irregular observa- tions. Usually Millstone Hill radar provides three (sometimes more) local height $\mathrm{Ne}, \mathrm{Te}, \mathrm{Ti}$ and $\mathrm{Vz}$ profiles per hour, with a $21-\mathrm{km}$ height resolution. We had to use a 3$4 \mathrm{~h}$ period of observation to calculate median height profiles with the standard deviations (SD) at each height. These median profiles were then smoothed by a polynomial fit up to the 5th order to be used in our analysis.

EISCAT multi-pulse observations provide excellent height profiles with a $3-\mathrm{km}$ height resolution in the $87-260 \mathrm{~km}$ height range. Due to frequent (every $2-5 \mathrm{~min}$ ) observations, median profiles can be calculated over a $1-2 \mathrm{~h}$ period; therefore, for the interesting cases, two different periods within one day can be considered for analysis (24/25 October 1990). Usually the periods around noon of maximal stability in $N m \mathrm{~F} 2$ and $h m \mathrm{~F} 2$ variations were selected to decrease the scatter and provide reliable median $N e(\mathrm{~h})$ profiles. Unlike Millstone Hill the EISCAT $N e(\mathrm{~h})$ profiles are not normalized by $f o \mathrm{~F} 2$ for each particular experiment, and this may result in wrong relative deviations when disturbed and reference days are compared. Therefore, the following procedure was applied. Long-pulse observations are known to provide reliable relative $N e(\mathrm{~h})$ profiles at the F2-region heights. Using the long-pulse $N m \mathrm{~F} 2 / N e(220 \mathrm{~km})$ ratio, the multi-pulse $N m \mathrm{~F} 2$ value was calculated assuming that relative $\mathrm{Ne}(\mathrm{h})$ height profiles are the same in the $(220 \mathrm{~km}-h m \mathrm{~F} 2)$ height range both for long-pulse and multi-pulse observations. This calculated $N m \mathrm{~F} 2$ was then normalized by the observed $f o \mathrm{~F} 2$ value measured by the Troms $\varnothing$ or Kiruna ionosondes. Then the whole $\mathrm{Ne}(h)$ multi-pulse profile was normalized by a corresponding factor.

The observations were grouped by 4 seasons regardless of the solar activity level. Since we analyzed only sunlit conditions EISCAT winter observations were not included. The list of analyzed dates (disturbed/reference), along with daily $A_{p}$ and $F_{10.7}$ indices, are given in Tables 1 and 2 for Millstone Hill and EISCAT, correspondingly. The ratios $r=N$ dist $/ N$ ref, along with absolute errors for $N m \mathrm{~F} 2$ and $N e$ at 5 heights $(160-200 \mathrm{~km})$, are given in the tables. Overall, 37 cases from Millstone Hill and 26 cases from EISCAT were analyzed. The observations are seen to overlap all levels of solar activity from the deep minima in 1986, 1996 to the maximum in 1990-1991. A strong scatter in observations for some dates (especially at Millstone Hill) results in abnormal SD values, and such cases are marked by dashes in Tables 1 and 2. With regard to this, it should be noted that while some wrong (due to occasional scatter) $\mathrm{Ne}$ values may strongly affect the calculated SD, the median values used in our analysis are much less sensitive to such scatter and are more reliable compared to mean $\mathrm{Ne}$ values.

Daily $A_{p}$ index is known to be a rather poor indicator of ionospheric disturbances. Therefore, one may find days in Tables 1 and 2 with relatively low $A_{p}$ values, which in fact were disturbed due to the preceding disturbed periods (e.g. 7 May 1986, 28 September 1995 from Table 1 or 14 August 1985, 26 March 1998 from Table 2). Due to this delay in the occurrence of ionospheric disturbances, the reference days may have relatively high $A_{p}$ indices, but in fact they were 
Table 1. List of Millstone Hill observations (disturbed/reference days), together with daily $A_{p}$ and $F_{10.7}$ indices. Observed $r N m$ F 2 and $r N e$ at $160-200 \mathrm{~km}$ heights are given, together with absolute deviations (dashes correspond to large scatter in data when calculated standard deviations are unreliable). G-conditions means the absence of the F2-layer peak, LT=UT-5

\begin{tabular}{|c|c|c|c|c|c|c|c|c|c|}
\hline \multicolumn{10}{|c|}{ Winter } \\
\hline Dates & UT & $A p$ & $F_{10.7}$ & $r N m \mathrm{~F} 2$ & $r N e(160)$ & $r N e(170)$ & $r N e(180)$ & $r N e(190)$ & $r N e(200)$ \\
\hline 15/13 Jan 1988 & 15:00-20:00 & $63 / 7$ & $112.4 / 108.1$ & $0.42 \pm 0.13$ & $1.08 \pm 0.32$ & $0.92 \pm 0.22$ & $0.76 \pm 0.18$ & $0.62 \pm 0.14$ & $0.52 \pm 0.11$ \\
\hline 11/14 Jan 1990 & 18:00-21:00 & $18 / 8$ & $169.5 / 165.9$ & $1.06 \pm 0.23$ & $1.45 \pm 0.92$ & $1.34 \pm 0.73$ & $1.23 \pm 0.62$ & $1.14 \pm 0.47$ & $1.04 \pm 0.46$ \\
\hline 25/23 Jan 1993 & 17:00-20:00 & $25 / 4$ & $105.8 / 106.0$ & $1.37 \pm 0.48$ & $1.12 \pm 0.54$ & $1.09 \pm 0.47$ & $1.06 \pm 0.45$ & $1.06 \pm 0.42$ & $1.08 \pm 0.39$ \\
\hline 26/23 Jan 1993 & 17:00-20:00 & $22 / 4$ & $106.5 / 106.0$ & $1.15 \pm 0.26$ & $1.23 \pm 0.59$ & $1.15 \pm 0.50$ & $1.09 \pm 0.53$ & $1.06 \pm 0.45$ & $1.06 \pm 0.40$ \\
\hline 30/29 Nov 1994 & $15: 30-18: 35$ & $21 / 9$ & $78.3 / 79.6$ & $0.80 \pm 0.20$ & $0.82 \pm 0.15$ & $0.83 \pm 0.18$ & $0.83 \pm 0.17$ & $0.82 \pm 0.15$ & $0.80 \pm 0.14$ \\
\hline 1 Dec/29 Nov 1994 & $15: 30-18: 40$ & $18 / 9$ & 79.1/79.6 & $1.20 \pm 0.24$ & $1.03 \pm 0.18$ & $1.03 \pm 0.16$ & $1.04 \pm 0.15$ & $1.04 \pm 0.13$ & $1.05 \pm 0.16$ \\
\hline 10/9 Jan 1997 & $17: 00-19: 20$ & $32 / 5$ & $75.4 / 73.7$ & $0.52 \pm 0.04$ & $0.81 \pm 0.18$ & $0.69 \pm 0.13$ & $0.60 \pm 0.09$ & $0.55 \pm 0.07$ & $0.48 \pm 0.06$ \\
\hline 7/9 Nov 1997 & 17:00-20:00 & $44 / 11$ & $94.4 / 86.4$ & $0.58 \pm 0.06$ & $0.97 \pm 0.40$ & $0.77 \pm 0.26$ & $0.63 \pm 0.17$ & $0.56 \pm 0.13$ & $0.53 \pm 0.10$ \\
\hline 11/10 Feb 1999 & 16:00-18:00 & $20 / 6$ & $163.5 / 152.4$ & $1.26-$ & $0.90-$ & $0.89-$ & $0.87-$ & $0.86-$ & $0.86-$ \\
\hline 14/15 Feb 2001 & $16: 30-18: 30$ & $18 / 5$ & 137.9/135.1 & $0.86 \pm 0.05$ & $0.45 \pm 0.11$ & $0.51 \pm 0.07$ & $0.57 \pm 0.07$ & $0.61 \pm 0.06$ & $0.65 \pm 0.06$ \\
\hline \multicolumn{10}{|c|}{ Spring } \\
\hline Dates & UT & $A p$ & $F_{10.7}$ & $r N m \mathrm{~F} 2$ & $r N e(160)$ & $r N e(170)$ & $r N e(180)$ & $r N e(190)$ & $r N e(200)$ \\
\hline 18/17 Mar 1990 & $16: 30-19: 30$ & $35 / 3$ & $196.4 / 182.0$ & $1.07 \pm 0.14$ & $1.02 \pm 0.28$ & $1.00 \pm 0.20$ & $0.99 \pm 0.18$ & $0.97 \pm 0.18$ & $0.96 \pm 0.18$ \\
\hline 20/17 Mar 1990 & $16: 30-19: 30$ & $30 / 3$ & $223.9 / 182.0$ & $0.88 \pm 0.09$ & $1.08 \pm 0.45$ & $1.02 \pm 0.34$ & $0.96 \pm 0.22$ & $0.90 \pm 0.23$ & $0.85 \pm 0.23$ \\
\hline 21/17 Mar 1990 & $17: 20-18: 55$ & $76 / 3$ & $227.6 / 182.0$ & $0.57 \pm 0.11$ & $1.02 \pm 0.36$ & $0.94 \pm 0.30$ & $0.86 \pm 0.27$ & $0.78 \pm 0.23$ & $0.72 \pm 0.20$ \\
\hline 22/17 Mar 1990 & 18:20-20:00 & $28 / 3$ & $243.1 / 182.0$ & $0.42 \pm 0.10$ & $0.94 \pm 0.35$ & $0.84 \pm 0.29$ & $0.75 \pm 0.26$ & $0.66 \pm 0.21$ & $0.59 \pm 0.18$ \\
\hline 9/7 Apr 1990 & 16:40-20:00 & $34 / 8$ & $146.8 / 155.0$ & $0.48 \pm 0.08$ & $0.86 \pm 0.24$ & $0.83 \pm 0.21$ & $0.80 \pm 0.19$ & $0.76 \pm 0.15$ & $0.72 \pm 0.12$ \\
\hline 10/7 Apr 1990 & 16:00-19:00 & $124 / 8$ & $149.3 / 155.0$ & $0.06 \pm 0.01$ & $0.90 \pm 0.19$ & $0.79 \pm 0.15$ & $0.67 \pm 0.12$ & $0.56 \pm 0.08$ & $0.45 \pm 0.05$ \\
\hline 11/7 Apr 1990 & 16:00-20:00 & $64 / 8$ & $160.8 / 155.0$ & $0.57-$ & $1.01-$ & $0.99-$ & $0.97-$ & $0.94-$ & $0.91-$ \\
\hline 21/14 Mar 1996 & 18:00-20:30 & $38 / 9$ & $70.4 / 70.8$ & $0.89-$ & $0.70-$ & $0.72-$ & $0.74-$ & $0.76-$ & $0.79-$ \\
\hline 18/16 Apr 1996 & 17:00-20:00 & $25 / 9$ & $70.1 / 68.3$ & $1.30 \pm 0.24$ & $1.15 \pm 0.29$ & $1.08 \pm 0.21$ & $1.08 \pm 0.17$ & $1.12 \pm 0.15$ & $1.22 \pm 0.15$ \\
\hline 17/19 Apr 1999 & 17:00-20:00 & $47 / 12$ & $115.7 / 110.0$ & $0.31 \pm 0.07$ & $0.93 \pm 0.19$ & $0.85 \pm 0.15$ & $0.76 \pm 0.12$ & $0.68 \pm 0.09$ & $0.60 \pm 0.09$ \\
\hline 6/13 Apr 2000 & 17:00-20:00 & $82 / 6$ & $177.7 / 164.0$ & $1.14-$ & $0.65-$ & $0.61-$ & $0.59-$ & $0.57-$ & $0.56-$ \\
\hline 13/17 Apr 2001 & 15:00-19:00 & $50 / 6$ & $137.0 / 126.0$ & $0.48 \pm 0.08$ & $0.78 \pm 0.10$ & $0.74 \pm 0.09$ & $0.68 \pm 0.07$ & $0.60 \pm 0.06$ & $0.53 \pm 0.05$ \\
\hline 18/17 Apr 2001 & $16: 30-19: 30$ & $50 / 6$ & $132.0 / 126.0$ & $0.62 \pm 0.08$ & $0.87 \pm 0.11$ & $0.82 \pm 0.10$ & $0.78 \pm 0.09$ & $0.75 \pm 0.09$ & $0.73 \pm 0.08$ \\
\hline
\end{tabular}

Summer

\begin{tabular}{|c|c|c|c|c|c|c|c|c|c|}
\hline Dates & UT & $A p$ & $F_{10.7}$ & $r N m \mathrm{~F} 2$ & $r N e(160)$ & $r N e(170)$ & $r N e(180)$ & $r N e(190)$ & $r N e(200)$ \\
\hline 6/8 May 1986 & $18: 30-22: 00$ & $67 / 7$ & $69.8 / 69.5$ & $0.75 \pm 0.20$ & $0.88 \pm 0.49$ & $0.84 \pm 0.40$ & $0.77 \pm 0.29$ & $0.71 \pm 0.21$ & $0.65 \pm 0.18$ \\
\hline 7/8 May 1986 & 19:00-22:00 & $12 / 7$ & $69.9 / 69.5$ & $0.81 \pm 0.11$ & $0.84 \pm 0.40$ & $0.85 \pm 0.36$ & $0.84 \pm 0.26$ & $0.80 \pm 0.16$ & $0.78 \pm 0.15$ \\
\hline 6/8 June 1991 & 19:00-21:00 & $49 / 26$ & $241.3 / 250.7$ & $1.13 \pm 0.18$ & $1.18 \pm 0.96$ & $1.21 \pm 0.92$ & $1.24 \pm 0.89$ & $1.26 \pm 0.85$ & $1.29 \pm 0.78$ \\
\hline 9/8 June 1991 & 19:00-21:00 & $58 / 26$ & $245.3 / 250.7$ & $0.55 \pm 0.09$ & $0.99 \pm 0.53$ & $0.97 \pm 0.48$ & $0.94 \pm 0.45$ & $0.88 \pm 0.40$ & $0.81 \pm 0.36$ \\
\hline 10/8 June 1991 & 19:00-21:00 & $119 / 26$ & $246.2 / 250.7$ & $0.43 \pm 0.11$ & $0.99 \pm 0.53$ & $0.95 \pm 0.48$ & $0.89 \pm 0.43$ & $0.83 \pm 0.38$ & $0.76 \pm 0.32$ \\
\hline 4/1 Aug 1992 & 17:00-20:00 & $15 / 8$ & $130.9 / 110.3$ & $1.34 \pm 0.10$ & $1.14 \pm 0.37$ & $1.09 \pm 0.10$ & $1.04 \pm 0.11$ & $1.02 \pm 0.14$ & $1.02 \pm 0.13$ \\
\hline 5/1 Aug 1992 & $17: 30-20: 30$ & $35 / 8$ & $130.5 / 110.3$ & $0.58 \pm 0.24$ & $0.85 \pm 0.49$ & $0.87 \pm 0.45$ & $0.86 \pm 0.44$ & $0.82 \pm 0.41$ & $0.76 \pm 0.39$ \\
\hline 14/15 Aug 1994 & 15:00-18:00 & $26 / 13$ & 88.9/81.4 & $0.81 \pm 0.08$ & $0.95 \pm 0.06$ & $0.91 \pm 0.07$ & $0.89 \pm 0.06$ & $0.86 \pm 0.06$ & $0.84 \pm 0.06$ \\
\hline 15/6 Jul 2000 & $15: 20-19: 20$ & $164 / 5$ & $213.1 / 174.3$ & $1.38 \pm 0.32$ & $1.05 \pm 0.14$ & $1.09 \pm 0.16$ & $1.12 \pm 0.14$ & $1.12 \pm 0.13$ & $1.11 \pm 0.12$ \\
\hline 16/6 Jul 2000 & 15:30-19:30 & $50 / 5$ & $218.9 / 174.3$ & G-cond & $1.02 \pm 0.14$ & $1.05 \pm 0.15$ & $1.03 \pm 0.14$ & $0.97 \pm 0.12$ & $0.89 \pm 0.11$ \\
\hline
\end{tabular}

Autumn

\begin{tabular}{lccccccccc}
\hline Dates & $\mathrm{UT}$ & $A p$ & $F_{10.7}$ & $r N m \mathrm{~F} 2$ & $r N e(160)$ & $r N e(170)$ & $r N e(180)$ & $r N e(190)$ & $r N e(200)$ \\
\hline 28/25 Sep 1995 & $15: 00-18: 00$ & $15 / 4$ & $72.7 / 74.0$ & $0.59-$ & $0.94-$ & $0.91-$ & $0.86-$ & $0.80-$ & $0.76-$ \\
7/5 Oct 1997 & $17: 00-20: 00$ & $44 / 7$ & $83.5 / 84.4$ & $0.52 \pm 0.06$ & $0.84 \pm 0.34$ & $0.77 \pm 0.28$ & $0.70 \pm 0.21$ & $0.64 \pm 0.17$ & $0.59 \pm 0.13$ \\
19/20 Oct 1998 & $16: 00-20: 00$ & $62 / 22$ & $117.7 / 121.2$ & $0.35 \pm 0.05$ & $0.78 \pm 0.40$ & $0.68 \pm 0.27$ & $0.59 \pm 0.19$ & $0.51 \pm 0.14$ & $0.45 \pm 0.11$ \\
15/7 Oct 1999 & $17: 00-18: 30$ & $31 / 5$ & $198.2 / 129.4$ & $1.63 \pm 0.13$ & $1.05 \pm 0.18$ & $1.04 \pm 0.14$ & $1.06 \pm 0.14$ & $1.08 \pm 0.13$ & $1.10 \pm 0.10$ \\
\hline
\end{tabular}


Table 2. List of EISCAT observations (disturbed/reference days), together with daily $A_{p}$ and $F_{10.7}$ indices. Observed $r N m \mathrm{~F} 2$ and $r N e$ at $160-200 \mathrm{~km}$ heights are given, together with absolute deviations (dashes correspond to large scatter in data when calculated standard deviations are unreliable). G-conditions means the absence of the F2-layer peak, LT=UT+1

\begin{tabular}{|c|c|c|c|c|c|c|c|c|c|}
\hline \multicolumn{10}{|c|}{ Spring } \\
\hline Dates & UT & $A p$ & $F_{10.7}$ & $r N m \mathrm{~F} 2$ & $r N e(160)$ & $r N e(170)$ & $r N e(180)$ & $r N e(190)$ & $r N e(200)$ \\
\hline 10/9 Apr 1990 & $13: 15-14: 15$ & $124 / 34$ & $149.3 / 146.8$ & G-cond & $1.12 \pm 0.27$ & $1.03 \pm 0.29$ & $0.94 \pm 0.23$ & $0.84 \pm 0.25$ & $0.78 \pm 0.24$ \\
\hline 3/2 Apr 1992 & $14: 00-15: 00$ & $32 / 6$ & $159.7 / 161.2$ & $0.16 \pm 0.07$ & $0.88 \pm 0.19$ & $0.83 \pm 0.10$ & $0.75 \pm 0.12$ & $0.61 \pm 0.09$ & $0.47 \pm 0.06$ \\
\hline 20/19 Mar 1996 & $11: 00-12: 30$ & $23 / 15$ & $69.3 / 69.9$ & $0.63 \pm 0.06$ & $0.82 \pm 0.27$ & $0.84 \pm 0.26$ & $0.83 \pm 0.35$ & $0.76 \pm 0.21$ & $0.66 \pm 0.15$ \\
\hline 21/19 Mar 1996 & 11:00-12:30 & $38 / 15$ & $70.4 / 69.9$ & $0.88 \pm 0.08$ & $0.87 \pm 0.22$ & $0.88 \pm 0.23$ & $0.91 \pm 0.29$ & $0.91 \pm 0.21$ & $0.89 \pm 0.25$ \\
\hline 25/24 Mar 1998 & $10: 30-12: 00$ & $16 / 7$ & $115.0 / 120.6$ & $0.81 \pm 0.15$ & $1.00 \pm 0.47$ & $0.95 \pm 0.39$ & $0.90 \pm 0.46$ & $0.84 \pm 0.31$ & $0.78 \pm 0.31$ \\
\hline 26/24 Mar 1998 & $10: 30-12: 00$ & $12 / 7$ & $110.0 / 120.6$ & $0.73 \pm 0.07$ & $1.04 \pm 0.42$ & $1.00 \pm 0.42$ & $0.95 \pm 0.40$ & $0.88 \pm 0.29$ & $0.80 \pm 0.24$ \\
\hline 27/24 Mar 1998 & $10: 30-12: 00$ & $15 / 7$ & $108.1 / 120.6$ & $0.73 \pm 0.07$ & $1.04 \pm 0.40$ & $1.00 \pm 0.44$ & $0.94 \pm 0.39$ & $0.84 \pm 0.33$ & $0.71 \pm 0.28$ \\
\hline 9/8 Mar 1999 & $13: 00-14: 30$ & $21 / 12$ & $127.1 / 126.9$ & $0.41 \pm 0.06$ & $1.23 \pm 0.80$ & $1.04 \pm 0.46$ & $0.83 \pm 0.58$ & $0.64 \pm 0.42$ & $0.49 \pm 0.41$ \\
\hline 10/8 Mar 1999 & $11: 30-13: 00$ & $34 / 12$ & $135.4 / 126.9$ & $0.63 \pm 0.05$ & $1.00 \pm 0.55$ & $0.93 \pm 0.37$ & $0.82 \pm 0.33$ & $0.72 \pm 0.31$ & $0.62 \pm 0.17$ \\
\hline
\end{tabular}

\begin{tabular}{lccccccccc}
\hline \multicolumn{7}{c}{ Summer } \\
\hline Dates & UT & $A p$ & $F_{10.7}$ & $r N m \mathrm{~F} 2$ & $r N e(160)$ & $r N e(170)$ & $r N e(180)$ & $r N e(190)$ & $r N e(200)$ \\
\hline 13/6 Aug 1985 & $14: 30-15: 30$ & $41 / 3$ & $68.9 / 77.9$ & $0.68 \pm 0.15$ & $0.89 \pm 0.16$ & $0.83 \pm 0.12$ & $0.80 \pm 0.09$ & $0.76 \pm 0.07$ & $0.74 \pm 0.06$ \\
14/6 Aug 1985 & $11: 30-13: 00$ & $11 / 3$ & $69.3 / 77.9$ & $0.79 \pm 0.03$ & $0.83 \pm 0.02$ & $0.82 \pm 0.02$ & $0.82 \pm 0.02$ & $0.81 \pm 0.03$ & $0.81 \pm 0.03$ \\
14/13 June 1988 & $12: 15-13: 30$ & $20 / 6$ & $111.7 / 115.0$ & $0.56 \pm 0.03$ & $0.82 \pm 0.24$ & $0.80 \pm 0.39$ & $0.77 \pm 0.34$ & $0.72 \pm 0.36$ & $0.65 \pm 0.23$ \\
1/6 Sep 1988 & $11: 00-12: 30$ & $21 / 3$ & $191.3 / 152.4$ & $0.55 \pm 0.03$ & $0.92 \pm 0.19$ & $0.88 \pm 0.19$ & $0.80 \pm 0.21$ & $0.72 \pm 0.17$ & $0.65 \pm 0.16$ \\
28/31 Aug 1989 & $12: 00-13: 30$ & $22 / 6$ & $174.1 / 208.9$ & $0.83 \pm 0.06$ & $0.88 \pm 0.38$ & $0.88 \pm 0.42$ & $0.89 \pm 0.47$ & $0.91 \pm 0.40$ & $0.92 \pm 0.36$ \\
30/31 Aug 1989 & $10: 30-12: 00$ & $17 / 6$ & $192.0 / 208.9$ & $1.28 \pm 0.12$ & $1.05 \pm 0.39$ & $1.07 \pm 0.55$ & $1.11 \pm 0.51$ & $1.14 \pm 0.59$ & $1.14 \pm 0.81$ \\
13/5 Jun 1990 & $12: 20-13: 40$ & $70 / 5$ & $208.8 / 153.7$ & $0.46 \pm 0.03$ & $0.95 \pm 0.17$ & $0.90 \pm 0.12$ & $0.87 \pm 0.15$ & $0.81 \pm 0.15$ & $0.74 \pm 0.19$ \\
5/4 Aug 1992 & $11: 00-12: 00$ & $35 / 15$ & $130.5 / 130.9$ & $0.52 \pm 0.06$ & $0.86 \pm 0.05$ & $0.84 \pm 0.07$ & $0.80 \pm 0.07$ & $0.72 \pm 0.08$ & $0.63 \pm 0.06$ \\
15/14 May 1997 & $15: 00-16: 30$ & $56 / 6$ & $73.0 / 73.5$ & G-cond. & $1.23 \pm 0.71$ & $1.07 \pm 0.59$ & $0.91 \pm 0.48$ & $0.78 \pm 0.37$ & $0.68 \pm 0.30$ \\
27/26 Jun 1997 & $10: 30-12: 00$ & $17 / 4$ & $71.7 / 71.8$ & $1.28 \pm 0.16$ & $0.91 \pm 0.17$ & $0.94 \pm 0.18$ & $0.94 \pm 0.21$ & $0.97 \pm 0.23$ & $0.94 \pm 0.24$ \\
\hline & & & & & & & & \\
\hline Dates & & & & & & & & \\
\hline 22/21 Sep 1987 & $11: 00-13: 00$ & $29 / 10$ & $81.3 / 83.0$ & $0.83 \pm 0.08$ & $0.78 \pm 0.23$ & $0.79 \pm 0.27$ & $0.80 \pm 0.24$ & $0.79 \pm 0.27$ & $0.76 \pm 0.24$ \\
23/21 Sep 1987 & $11: 00-13: 00$ & $17 / 10$ & $80.4 / 83.0$ & $0.69 \pm 0.12$ & $0.88 \pm 0.26$ & $0.87 \pm 0.31$ & $0.85 \pm 0.33$ & $0.83 \pm 0.31$ & $0.79 \pm 0.28$ \\
24/23 Sep 1998 & $10: 00-12: 00$ & $28 / 11$ & $135.4 / 143.2$ & $0.76 \pm 0.07$ & $1.04 \pm 0.24$ & $1.04 \pm 0.33$ & $1.05 \pm 0.38$ & $1.04 \pm 0.32$ & $1.01 \pm 0.36$ \\
10/9 Oct 1990 & $11: 30-12: 30$ & $48 / 12$ & $194.7 / 183.9$ & $0.28 \pm 0.03$ & $0.74 \pm 0.21$ & $0.67 \pm 0.22$ & $0.59 \pm 0.21$ & $0.49 \pm 0.16$ & $0.39 \pm 0.11$ \\
11/9 Oct 1990 & $10: 00-11: 00$ & $42 / 12$ & $205.1 / 183.9$ & $0.67 \pm 0.06$ & $0.73 \pm 0.18$ & $0.67 \pm 0.22$ & $0.59 \pm 0.26$ & $0.49 \pm 0.16$ & $0.40 \pm 0.12$ \\
24/25 Oct 1990 & $11: 00-12: 30$ & $25 / 9$ & $157.5 / 161.8$ & $1.24 \pm 0.05$ & $0.94-$ & $0.95-$ & $0.92-$ & $0.85-$ & $0.76-$ \\
24/25 Oct 1990 & $13: 30-15: 00$ & $25 / 9$ & $157.5 / 161.8$ & $0.53 \pm 0.14$ & $0.88-$ & $0.79-$ & $0.72-$ & $0.64-$ & $0.56-$ \\
\hline
\end{tabular}

only slightly disturbed (e.g. 9 April 1990, 4 August 1992 from Table 2). The choice of 8 June 1991 and 20 October 1998 (Table 1) as the reference days is due to the absence of available quiet days nearby.

\section{Data analysis}

Millstone Hill observations (Table 1) show both negative and positive storm effects for all seasons, but negative deviations prevail. As a rule, positive deviations are relatively small compared to negative ones. At EISCAT (the auroral zone) negative deviations dominate (Table 2). Some cases of small positive storm effects (30/31 August 1989, 24/23 September 1998) may be related to uncertainties of $f_{o} \mathrm{~F} 2$ readings from ionograms used for the $\mathrm{Ne}(\mathrm{h})$ profile normalization. On the other hand, positive deviations are more pronounced at lower heights $(160 \mathrm{~km})$, and this may be due to particle precipitation effects during disturbed periods.

Usually the amplitude of deviation increases with height (a decrease in $r \mathrm{Ne}$ in Tables 1 and 2), especially for negative storm effect, but the inverse type of dependence is possible as well (26/23 January 1993, 11/14 January 1990; 14/15 February 2001; 4/1 August 1992 from Table 1 or 21/19 March 1996, 28/31 August 1989 from Table 2).

For the convenience of presentation we will consider $\delta N e=r N e-1$, together with $r N e$. Figure 1 shows the $\delta N e$ (at $180 \mathrm{~km})$ versus $\delta N m \mathrm{~F} 2=(N m \mathrm{~F} 2$ dist $N m$ F2ref)/NmF2ref dependence for Millstone Hill and EISCAT. Although the majority of points are clustering in the negative sector of the plots, there is an obvious relationship between the analyzed parameters. To check whether this dependence is significant, we put together the data for all sea- 
Table 3. Correlation between $\delta N e$ at F1-layer heights and $\delta N m \mathrm{~F} 2$ for Millstone Hill and EISCAT

\begin{tabular}{ccccccc}
\hline & \multicolumn{3}{c}{ Millstone Hill } & \multicolumn{3}{c}{ EISCAT } \\
$\begin{array}{c}\text { Height, } \\
\text { km }\end{array}$ & $\begin{array}{c}\text { Corr. } \\
\text { coeff. }\end{array}$ & F param. & $\begin{array}{c}\text { Confid. } \\
\text { level, } \%\end{array}$ & $\begin{array}{c}\text { Corr. } \\
\text { coeff. }\end{array}$ & F param. & $\begin{array}{c}\text { Confid. } \\
\text { level, \% }\end{array}$ \\
\hline 160 & 0.38 & 5.80 & 95 & 0.14 & 0.45 & None \\
170 & 0.50 & 11.7 & 99 & 0.44 & 5.18 & 95 \\
180 & 0.63 & 23.4 & 99 & 0.65 & 16.3 & 99 \\
190 & 0.73 & 40.0 & 99 & 0.75 & 28.7 & 99 \\
200 & 0.80 & 62.0 & 99 & 0.77 & 31.2 & 99 \\
\hline
\end{tabular}

sons from Tables 1 and 2 and calculated the correlation coefficients between $\delta N e(180)$ and $\delta N m \mathrm{~F} 2$. The test of statistical significance for this correlation was made with the Fisher's F-criterion (Pollard, 1977). The results are given in Table 3. The correlation coefficients are seen to be not very large but they are significant at the 95-99\% confidence level. The observations at $160 \mathrm{~km}$ show large scatter and look less reliable compared to higher altitudes.

The results by Buresova and Lastovicka (2001) and Buresova et al. (2002) show some seasonal effect (winter/summer and autumn/spring asymmetry) in the $\mathrm{NeF} 1 \mathrm{re}-$ action to the geomagnetic disturbances. We have calculated average $r \mathrm{Ne}$ from Tables 1 and 2 for different seasons. These average values, along with the standard deviations, are given in Table 4 for Millstone Hill and EISCAT. The storm effect is seen to be less in summer compared to other seasons at Millstone Hill. At EISCAT this summer effect is seen only with respect to autumn, but an autumn/spring asymmetry is clearly present in the storm effect. To check whether these seasonal differences are significant, we put together all heights in Table 4 and applied the Student's T-criterion (Pollard, 1977), which examines whether the difference between two average values is significant. At Millstone Hill the summer/winter difference is significant at the $90 \%$, summer/spring - at $99.9 \%$, summer/autumn - at $99.9 \%$ confidence level, while the autumn/spring difference is insignificant. At EISCAT the summer/autumn difference is significant at the $99 \%$, autumn/spring - at $97.5 \%$ confidence level, while the summer/spring difference is insignificant. Table 4 also shows the decrease with height in calculated $r \mathrm{Ne}$, indicating the increase in the storm effect with height for all seasons.

The results of the morphological analysis may be summarized as follows:

1. The storm effects may be positive and negative but negative deviations prevail. As a rule, positive storm effects are small compared to negative ones.

2. Usually the amplitude of the storm effect increases with height (especially for negative ones), but cases with the inverse type of dependence also take place both at Millstone Hill and EISCAT.
3. There is a direct and significant correlation between $\delta N e$ at $\mathrm{F} 1$-layer heights and $\delta N m \mathrm{~F} 2$, the correlation coefficients increasing with height.

4. At Millstone Hill the summer storm effects in $\delta N e$ are less compared to other seasons, but they are well detectable, nevertheless. At EISCAT an autumn/spring asymmetry in the storm effect is well pronounced, while the summer effect takes place only with respect to the autumnal season. These differences are statistically significant.

5. It should be stressed that in general a relatively small sensitivity of the F1-region to geomagnetic disturbances exists despite large storm perturbations in the thermospheric parameters (see later). This is quite different from the F2-layer storm behavior.

An interpretation of the revealed morphological features is given below based on the contemporary understanding of the ionosphere formation at F1-layer heights.

\section{Model calculations}

To understand the physical mechanism of the revealed F1layer storm effects, one should consider the aeronomic parameters responsible for the F1-layer formation during quiet and disturbed conditions. A method proposed by Mikhailov and Schlegel (1997), with later modifications (Mikhailov and Förster, 1999; Mikhailov and Schlegel, 2000) applied earlier to Millstone Hill observations (Mikhailov and Foster, 1997; Mikhailov and Förster, 1997, 1999) and EISCAT observations (Mikhailov and Schlegel, 1998; Mikhailov and Kofman, 2001) is used here. It allows us to find in a self-consistent way neutral composition $\left(\mathrm{O}, \mathrm{O}_{2}, \mathrm{~N}_{2}\right.$ concentrations), neutral temperature specified by three parameters $\left(T_{e x}, T_{120}, S\right)$, total EUV solar flux with $\lambda<1050 \AA$, and ion composition. Vertical plasma drift related to thermospheric winds and electric fields can also be derived with this method, but they are not used in the present analysis. The details of the method may be found in the above references; therefore, only the main idea is sketched here. The model used includes: transport process for $\mathrm{O}^{+}\left({ }^{4} \mathrm{~S}\right)$ and photochemical processes only for $\mathrm{O}^{+}\left({ }^{2} \mathrm{D}\right), \mathrm{O}^{+}\left({ }^{2} \mathrm{P}\right), \mathrm{O}_{2}^{+}\left(\mathrm{X}^{2} \prod\right)$, $\mathrm{N}^{+}, \mathrm{N}_{2}^{+}$and $\mathrm{NO}^{+}$ions in the $120-550 \mathrm{~km}$ height range. Depending on conditions the height interval can be changed (for instance, to avoid the precipitation effect at lower heights) and the observed electron concentration is used as the boundary condition. A two-component model of the solar EUV from Nusinov (1992) is used to calculate the photoionization rates in 35-wavelength intervals (100-1050 $\AA$ ). The photoionization and photo-absorption cross sections are obtained from Torr et al. (1979) and Richards and Torr (1988). Flowing afterglow laboratory measurements of the $\mathrm{O}^{+}+\mathrm{N}_{2}$ reaction rate constant by Hierl et al. (1997) are included as well. Vertical plasma drift used in the continuity equation for $\mathrm{O}^{+}$ions is obtained from the observed parameters as a 
Table 4. Observed seasonal variation of the $r \mathrm{Ne}$ values at F1-layer heights for Millstone Hill and EISCAT. Average daytime values along with standard deviations are given

\begin{tabular}{cccccccc}
$\begin{array}{c}\text { Height } \\
\text { km }\end{array}$ & Winter & Spring & Summer & Autumn & Spring & EISCAT \\
& & Summer & Autumn \\
\hline 160 & $0.99 \pm 0.27$ & $0.92 \pm 0.15$ & $0.99 \pm 0.12$ & $0.90 \pm 0.12$ & $1.00 \pm 0.13$ & $0.93 \pm 0.12$ & $0.86 \pm 0.11$ \\
170 & $0.92 \pm 0.24$ & $0.86 \pm 0.14$ & $0.98 \pm 0.12$ & $0.85 \pm 0.16$ & $0.94 \pm 0.08$ & $0.90 \pm 0.10$ & $0.83 \pm 0.14$ \\
180 & $0.87 \pm 0.23$ & $0.82 \pm 0.14$ & $0.96 \pm 0.14$ & $0.80 \pm 0.20$ & $0.87 \pm 0.07$ & $0.87 \pm 0.10$ & $0.79 \pm 0.17$ \\
190 & $0.83 \pm 0.23$ & $0.77 \pm 0.17$ & $0.93 \pm 0.17$ & $0.76 \pm 0.24$ & $0.78 \pm 0.11$ & $0.83 \pm 0.13$ & $0.73 \pm 0.20$ \\
200 & $0.81 \pm 0.25$ & $0.74 \pm 0.21$ & $0.89 \pm 0.19$ & $0.72 \pm 0.28$ & $0.69 \pm 0.14$ & $0.79 \pm 0.16$ & $0.67 \pm 0.23$ \\
\hline
\end{tabular}

difference between measured total vertical plasma velocity and diffusion velocity for $\mathrm{O}^{+}$ions. Collisions of $\mathrm{O}^{+}$ions with neutral $\mathrm{O}, \mathrm{O}_{2}, \mathrm{~N}_{2}$ and $\mathrm{NO}^{+}, \mathrm{O}_{2}^{+}, \mathrm{N}_{2}^{+}, \mathrm{N}^{+}$ions are taken into account. $\mathrm{All}^{+}$ion collision frequencies are taken from Banks and Kockarts (1973). Ion concentrations are known at each iteration step from fitting calculated $\mathrm{Ne}(h)$ to the experimental ones. Using standard multi-regressional methods we fit the calculated $\mathrm{Ne}(h)$ profile to the observed one and find the earlier mentioned aeronomic parameters. The estimated accuracy of the extracted thermospheric parameters is about $\pm 20-25 \%$ (Mikhailov and Schlegel, 1997, 2000).

Four cases (disturbed/quiet) of days presenting different seasons were analyzed. Winter and spring are presented by Millstone Hill observations on 7/9 November 1997 and 22/17 March 1990, with a well pronounced negative storm effect and increasing $\delta N e$ with height. Summer and autumn are presented by EISCAT observations on 13/5 June 1990 and 1/6 September 1988, with small storm effects at F1-layer heights. In fact, the 1/6 September case may be prescribed to summer and later, we will refer to June 1990 and September 1988 periods as "summer". Since winter and equinoctial periods demonstrate similar storm effects (Table 4), we will refer to November 1997 and March 1990 periods as "winter" in further discussion.

Millstone Hill observations during a very severe geomagnetic storm on 15-16 July 2000 were also analyzed. This period considered by Buresova et al. (2002) is distinguished by small F1-layer storm effects, despite the extremely strong geomagnetic storm with $A_{p}$ index up to 164 .

The selected EISCAT observations are characterized by small $(E<7 \mathrm{mV} / \mathrm{m}$ ) electric fields in order not to introduce additional effects (St.-Maurice and Schunk, 1979; Hubert and Kinzelin, 1992) to the model calculations. This allows us to consider the daytime auroral ionosphere as a midlatitude one (Farmer et al., 1984; Lathuillière and Brekke, 1985). However, EISCAT is located in the auroral zone, and particle precipitation takes place in some cases during disturbed periods. For instance, 25 September 1998 was not used in our analysis for this reason; a pronounced increase in Ne obviously related with particle precipitation took place at lower heights on 9 March 1999. But such cases are not numerous in our analysis.

The experimental $\mathrm{Ne}(h), \mathrm{Te}(h), \mathrm{Ti}(h)$ profiles were corrected for disturbed days when the calculated ion composi-
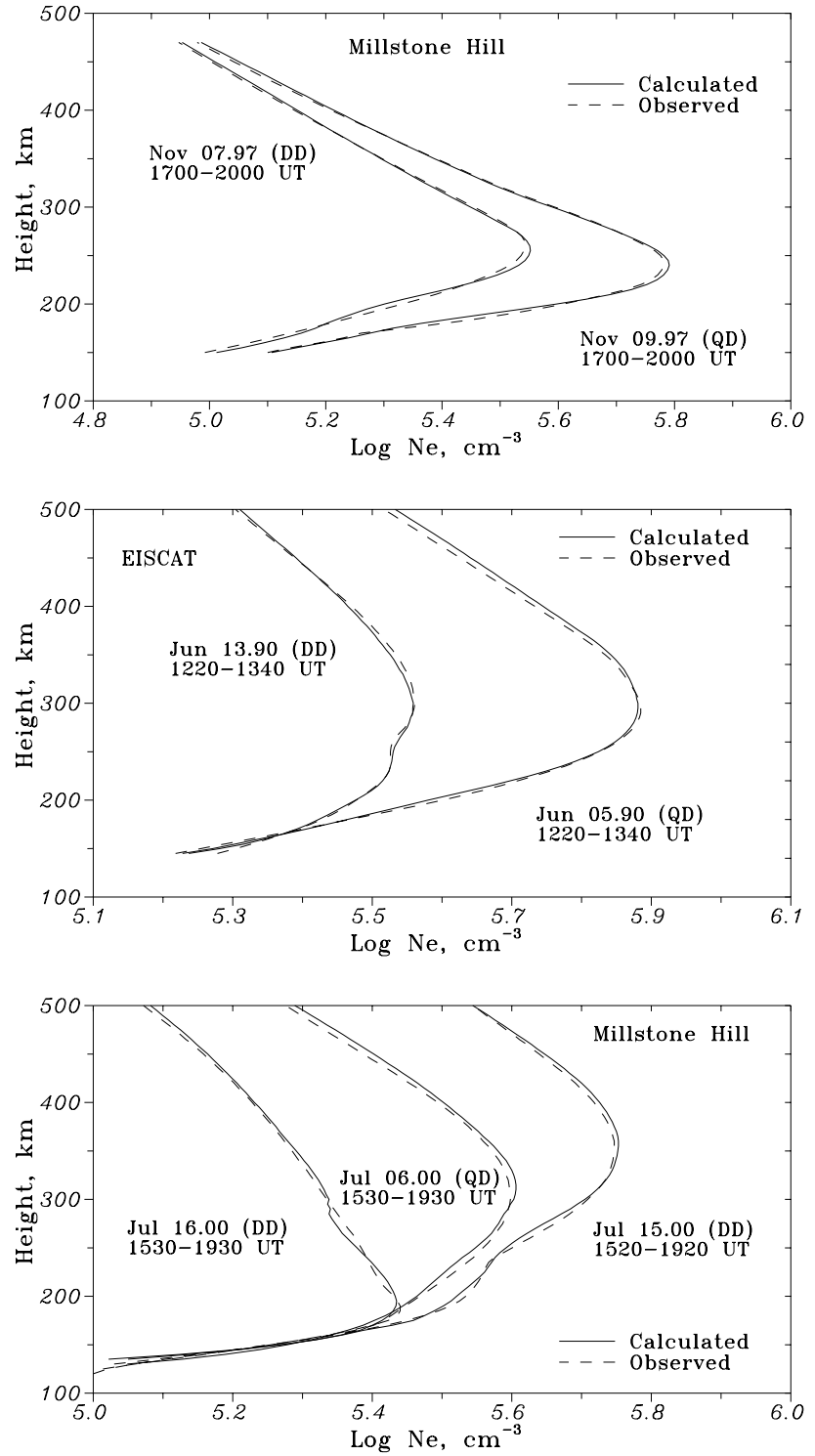

Fig. 2. Observed (corrected on ion composition) and calculated $\mathrm{Ne}(h)$ profiles for winter (7/9 November 1997), summer (13/5 June 1990) and a very severe geomagnetic storm on 15-16 July 2000.

tion $\left(\mathrm{O}^{+} / \mathrm{Ne}\right.$ ratio) was strongly different from the model one used in the incoherent scatter data analysis (Waldteufel, 

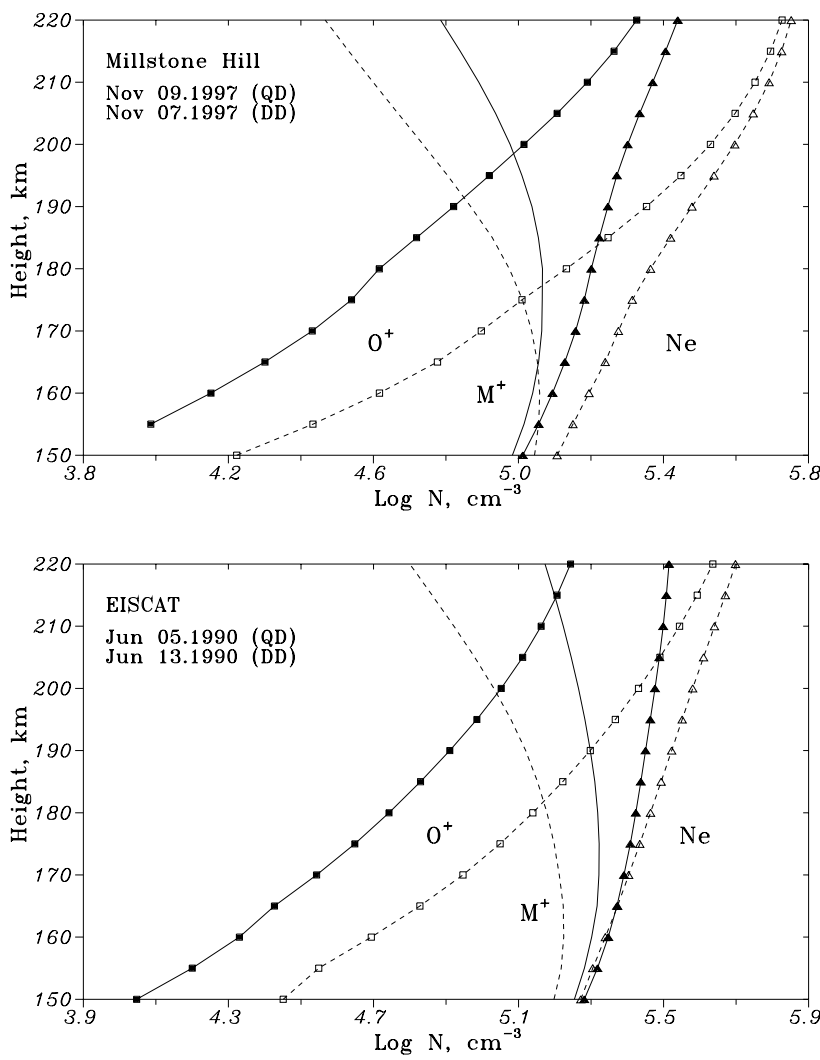

Fig. 3. Calculated distribution of atomic oxygen $\mathrm{O}^{+}$and molecular $\mathrm{M}^{+}$ions as well as their sum, Ne for winter (7 Nov/9 Nov 1997) and summer (13 Jun/5 Jun 1990) disturbances. Solid lines and filled symbols refer to the disturbed days.

1971; Mikhailov and Schlegel, 1997).

The observed and calculated $\mathrm{Ne}(h)$ profiles for winter 7/9 November 1997, summer 5/13 June 1990, and the severe summer storm conditions of 15-16 July 2000 are shown in Fig. 2. The selected periods are seen to exhibit strong storm effects in the F2-region, while the F1-region effects are small, especially in summer. The $15-16$ July 2000 period is very interesting, demonstrating a positive storm effect on 15 July and so-called "G-conditions" on 16 July, when the F2layer maximum has completely disappeared at usual heights. The quality of model $\mathrm{Ne}(h)$ fitting may be considered as acceptable. For further analysis we will need ion composition. The calculated distribution of $\mathrm{O}^{+}$and molecular ions $\mathrm{M}^{+}=\mathrm{O}_{2}^{+}+\mathrm{NO}^{+}$concentrations are shown in Fig. 3 for quiet (QD) and disturbed (DD) days.

\section{Interpretation}

Physical interpretation of the obtained results may be given from an analysis of a simple scheme of photochemical processes controlling the daytime ionosphere at F1-layer heights. The main processes are photoionization of neutral $[\mathrm{O}],\left[\mathrm{O}_{2}\right],\left[\mathrm{N}_{2}\right]$ by solar EUV radiation, the conversion of primary ions to molecular ones via ion-molecule reactions,
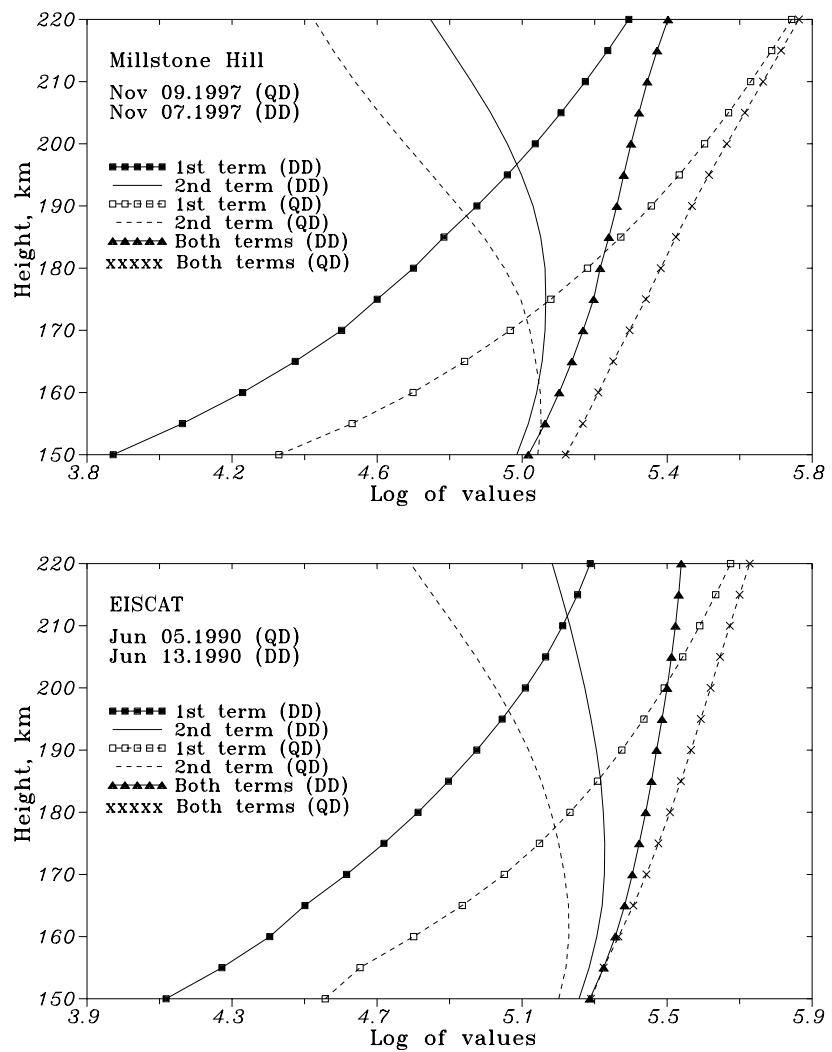

Fig. 4. Same as Fig. 3, but a simple analytical approach (Eq. 4) was used in the calculations. Note a close resemblance with Fig. 3.

followed by the dissociative recombination of molecular ions with electrons. This scheme of processes may be written as

$$
\begin{aligned}
& q\left(\mathrm{O}^{+}\right)=\left[\mathrm{O}^{+}\right]\left\{\gamma_{1}\left[\mathrm{~N}_{2}\right]+\gamma_{2}\left[\mathrm{O}_{2}\right]\right\} \\
& q\left(\mathrm{~N}_{2}^{+}\right)=\gamma_{3}[\mathrm{O}]\left[\mathrm{N}_{2}^{+}\right] \\
& q\left(\mathrm{O}_{2}^{+}\right)+\gamma_{2}\left[\mathrm{O}_{2}\right]\left[\mathrm{O}^{+}\right]=\alpha_{2}\left[\mathrm{O}_{2}^{+}\right] N_{e} \\
& \gamma_{1}\left[\mathrm{~N}_{2}\right]\left[\mathrm{O}^{+}\right]+\gamma_{3}[\mathrm{O}]\left[\mathrm{N}_{2}^{+}\right]=\alpha_{1}\left[\mathrm{NO}^{+}\right] N_{e} \\
& N_{e}=\left[\mathrm{O}^{+}\right]+\left[\mathrm{O}_{2}^{+}\right]+\left[\mathrm{NO}^{+}\right],
\end{aligned}
$$

where $q_{i}$ - primary ion production rates, $\gamma_{i}$ - ion-molecule reaction rate coefficients, and $\alpha_{i}$ - dissociative recombination rate coefficients. Equilibrium concentration of $\mathrm{N}_{2}^{+}$ions is negligible compared to the main ions (e.g. Goldberg and Blumle, 1970).

For the sake of simplicity we consider in accordance with Ivanov-Kholodny and Nikoljsky (1969) the ionosphere at F1-region heights consisting of atomic $\mathrm{O}^{+}$and molecular $\mathrm{M}^{+}=\mathrm{NO}^{+}+\mathrm{O}_{2}^{+}$ions. From Eq. (1) we have for $\mathrm{O}^{+}$ions $q\left(\mathrm{O}^{+}\right)=\beta\left[\mathrm{O}^{+}\right]$, where $\beta=\gamma_{1}\left[\mathrm{~N}_{2}\right]+\gamma_{2}\left[\mathrm{O}_{2}\right]$ and for molecular ions $\mathrm{M}^{+}=\mathrm{NO}^{+}+\mathrm{O}_{2}^{+}$, both produced by direct photoionization and via ion-molecule reactions, we may write

$q\left(\mathrm{O}^{+}\right)+q\left(\mathrm{M}^{+}\right)=q=\alpha_{a v e}\left[\mathrm{M}^{+}\right] N_{e}$,

where

$\alpha_{\text {ave }}=\alpha_{1} \frac{\left[\mathrm{NO}^{+}\right]}{\left[\mathrm{M}^{+}\right]}+\alpha_{2} \frac{\left[\mathrm{O}_{2}^{+}\right]}{\left[\mathrm{M}^{+}\right]}$ 

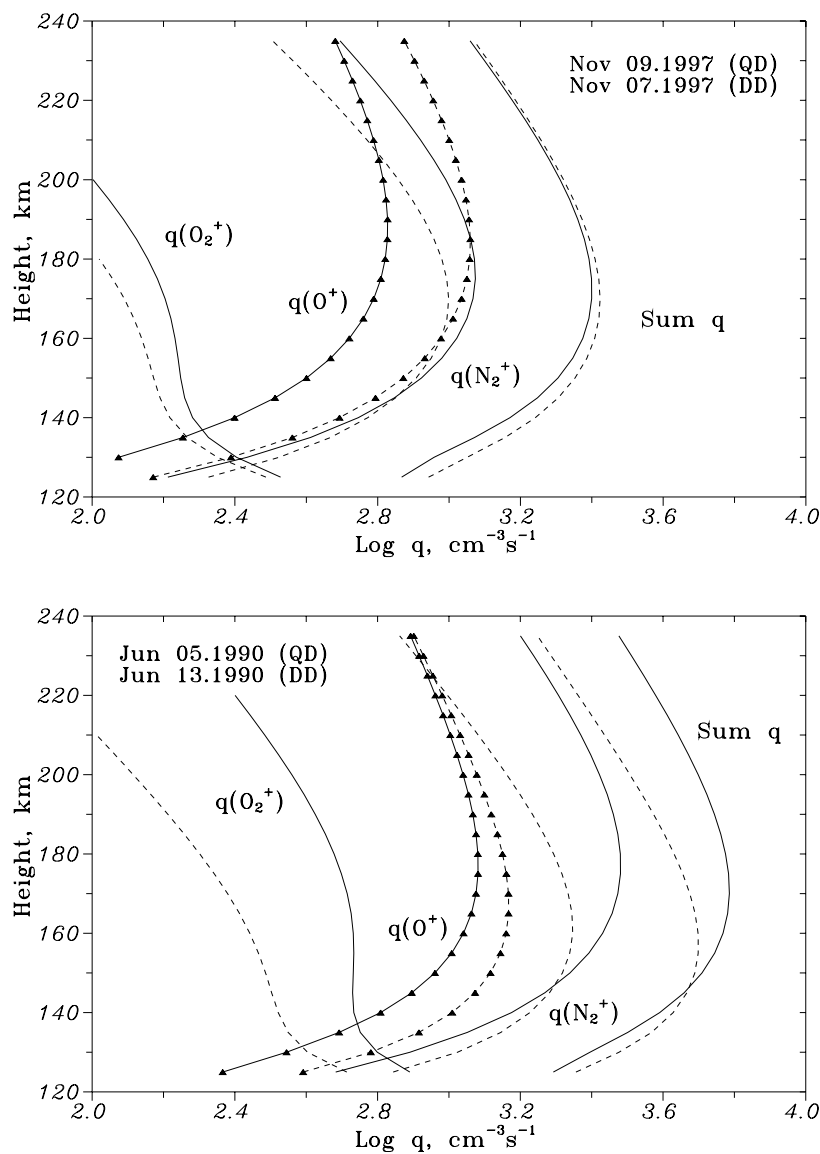

Fig. 5. Calculated ion production rates for the analyzed disturbances. Again solid lines refer to disturbed days.

is the average-weighted dissociative recombination rate coefficient. Keeping in mind that $\left[\mathrm{M}^{+}\right]=\mathrm{Ne}-\left[\mathrm{O}^{+}\right]$and $\left[\mathrm{O}^{+}\right]$ $=q\left(\mathrm{O}^{+}\right) / \beta$, we obtain from Eq. (2)

$N_{e}^{2}-N_{e} \frac{q\left(\mathrm{O}^{+}\right)}{\beta}-\frac{q}{\alpha_{\text {ave }}}=0$.

Equation (3) may be rewritten as

$N_{e}=\frac{q\left(\mathrm{O}^{+}\right)}{\beta}+\frac{q}{\alpha_{a v e} N_{e}}$.

The first term in Eq. (4) presents the $\mathrm{O}^{+}$ion concentration and the second term - the concentration of $\mathrm{M}^{+}$ions. The two terms of Eq. (4), as well as their sum, are shown in Fig. 4 for 7/9 November 1997 and 5/13 June 1990 to be compared with the model calculated distributions (Fig. 3) when the complete set of pertinent processes is taken into account. The two figures are seen to be very similar; therefore, our simplified approach (Eq. 4) may be used for physical interpretation.

5.1 Seasonal difference in the F1-layer reaction to geomagnetic storms

Our morphological analysis (Table 4), as well as the results by Buresova et al. (2002), indicate more pronounced F1- layer storm effects in winter and equinoxes compared to summer. The differences (disturbed minus quiet) for $\left[\mathrm{O}^{+}\right]$and $\left[\mathrm{M}^{+}\right]$, as well as for $\mathrm{Ne}$ at $180 \mathrm{~km}$, are shown in Table 5 for "winter" and "summer" cases.

Table 5 shows that $\left[\mathrm{O}^{+}\right]$and $\left[\mathrm{M}^{+}\right]$change in opposite directions. Normally $\left[\mathrm{O}^{+}\right]$decreases while $\left[\mathrm{M}^{+}\right]$always increases in disturbed conditions. The $\left[\mathrm{O}^{+}\right]$decrease usually prevails, especially in "winter", and this determines the negative sign of the storm effect observed in the majority of cases (Tables 1 and 2). The "summer" $\left[\mathrm{M}^{+}\right]$increase is larger compared to the "winter" one, and the resultant negative storm effect is less in summer due to this compensation. The 15-16 July 2000 storm effects will be discussed later.

Let us consider the aeronomic parameters responsible for such seasonal differences in $\left[\mathrm{O}^{+}\right]$and $\left[\mathrm{M}^{+}\right]$storm-time variations. Table 6 gives calculated changes (at $180 \mathrm{~km}$ ) in [O], $\left[\mathrm{O}_{2}\right],\left[\mathrm{N}_{2}\right], q\left(\mathrm{O}^{+}\right)$, in total ion production rate $q$, as well as in linear loss coefficient $\beta$. Generally, the atomic oxygen ion concentration decreases for disturbed periods, and this is due to a decrease in $q\left(\mathrm{O}^{+}\right)$and an increase in $\beta$ (see the first term in Eq. 4). The molecular ion concentration $\left[\mathrm{M}^{+}\right]$always increases for the storm periods (Table 5), but this is due to different reasons in "summer" and in "winter". The second term of Eq. (4) indicates that $\left[\mathrm{M}^{+}\right]$depends on three parameters. Our analysis has shown that the increase of the total ion production rate $q$ is the main channel for the $\left[\mathrm{M}^{+}\right]$increase in "summer", while $\alpha_{\text {ave }}$ and $\mathrm{Ne}$ changes are less, and they work in opposite directions, compensating each other to a great extent. In "winter" $q$ variations are small (Fig. 5 and Table 6) and the main contribution to the $\left[\mathrm{M}^{+}\right]$increase provides the decrease in $N e$, as this leads to a decrease in the $\mathrm{M}^{+}$recombination rate. Figure 5 (top panel) shows that quiet time $q\left(\mathrm{O}^{+}\right)$and $q\left(\mathrm{~N}_{2}^{+}\right)$are close at F1-layer heights in "winter", while the disturbed values varying in opposite directions compensate each other to a great extent. In "summer" the initial quiet time $q\left(\mathrm{O}^{+}\right)$and $q\left(\mathrm{~N}_{2}^{+}\right)$values differ essentially (Fig. 5, bottom) and the additional large increase in $q\left(\mathrm{~N}_{2}^{+}\right)$ and also in $q\left(\mathrm{O}_{2}^{+}\right)$overpowers the decrease in $q\left(\mathrm{O}^{+}\right)$. This results in a noticeable increase in the total ion production rate.

The F1-layer is formed in the vicinity of the total ion production rate maximum (Fig. 5), so the absorption of EUV radiation is not very large (the optical depth $\tau=1$ ) and the specific $q_{i}$ are roughly proportional to the concentration of the ionized neutral species. Therefore, the calculated variations in $q_{i}$ roughly reflect the variations in neutral composition. The calculated variations of molecular species concentrations (Table 6) clearly indicate the seasonal difference in the thermosphere reaction to the geomagnetic disturbances. This results in larger $\Delta q$ in "summer".

Some autumn/spring asymmetry in the F1-layer storm effect mentioned earlier can be related to an asymmetry in atomic oxygen annual variations in the thermosphere, with [O] being more abundant in late autumn compared to spring, according to the thermospheric model MSIS-86 (Hedin, 1987). In general, seasonal variations of the F1- 
Table 5. Differences at $180 \mathrm{~km}$ (disturbed-quiet) in atomic and molecular ion concentrations as well as in $N e$ for "winter" and "summer" disturbances

\begin{tabular}{cccc} 
Dates & $\Delta\left[\mathrm{O}^{+}\right] \times 10^{5} \mathrm{~cm}^{-3} \Delta\left[\mathrm{M}^{+}\right] \times 10^{5} \mathrm{~cm}^{-3}$ & $\Delta[\mathrm{Ne}] \times 10^{5} \mathrm{~cm}^{-3}$ \\
\hline \multicolumn{4}{c}{ "Winter" } \\
\hline 7/9 Nov 1997 & -0.95 & +0.22 & -0.73 \\
22/17 Mar 1990 & -1.07 & +0.26 & -0.81 \\
\hline \multicolumn{4}{c}{ "Summer" } \\
\hline 13/5 June 1990 & -0.83 & +0.57 & -0.26 \\
1/6 Sep 1988 & -0.78 & +0.41 & -0.37 \\
\hline \multicolumn{5}{c}{ "The 15/16 July 2000 storm" } \\
\hline 15/6 Jul 2000 & +0.08 & +0.14 & +0.22 \\
16/6 Jul 2000 & -0.22 & +0.11 & -0.11 \\
\hline
\end{tabular}

Table 6. Calculated variations at $180 \mathrm{~km}$ in neutral composition, ion production rates and linear loss coefficient for "winter" and "summer" disturbances

\begin{tabular}{ccccccc} 
Dates & $\Delta \log [\mathrm{O}]$ & $\Delta \log \left[\mathrm{O}_{2}\right]$ & $\Delta \log \left[\mathrm{N}_{2}\right]$ & $\Delta \log q\left(\mathrm{O}^{+}\right)$ & $\Delta \log q$ & $\Delta \log \beta$ \\
\hline \multicolumn{7}{c}{ "Winter" } \\
\hline 7/9 Nov 1997 & -0.190 & +0.220 & +0.170 & -0.237 & -0.017 & +0.259 \\
22/17 Mar 1990 & -0.025 & +0.245 & +0.155 & -0.133 & -0.022 & +0.167 \\
\hline \multicolumn{7}{c}{ "Summer" } \\
\hline 13/5 Jun 1990 & -0.084 & +0.428 & +0.249 & -0.069 & +0.144 & +0.351 \\
1/6 Sep 1988 & -0.162 & +0.339 & +0.256 & -0.149 & +0.127 & +0.304 \\
\hline \multicolumn{7}{c}{ “The 15/16 July 2000 storm" } \\
\hline 15/6 Jul 2000 & +0.169 & +0.106 & +0.05 & +0.155 & +0.06 & +0.07 \\
16/6 July 2000 & -0.349 & +0.213 & -0.02 & -0.191 & +0.02 & +0.08 \\
\hline \multicolumn{7}{c}{ "Height decreasing positive storm effect" } \\
\hline 11/14 Jan 1990 & -0.231 & -0.075 & -0.188 & 0.00 & 0.026 & -0.134 \\
\hline
\end{tabular}

layer storm effect magnitude reflect seasonal variations in the atomic oxygen concentration. Large [O] concentration during equinoctial and winter seasons results in a large contribution of $\left[\mathrm{O}^{+}\right]$ions to $\mathrm{Ne}$. Therefore, any storm-time decrease in $[\mathrm{O}]$ is essential and noticeable in the $\mathrm{Ne}$ variations, unlike in summer when the role of $\left[\mathrm{O}^{+}\right]$is much less compared to the influence of $\left[\mathrm{M}^{+}\right]$.

In summary, we may conclude that the less pronounced "summer" storm effect compared to the "winter" one is due to a stronger compensation of negative $\Delta\left[\mathrm{O}^{+}\right]$by positive $\Delta\left[\mathrm{M}^{+}\right]$in "summer". In turn, these seasonal differences just reflect the seasonal differences in neutral composition both during quiet and disturbed conditions.

\subsection{Height dependence of the storm effect}

Normally, the F1-layer storm effect increases with height (Tables 1, 2, and 4). This has a simple explanation based on the competition mechanism between $\Delta\left[\mathrm{O}^{+}\right]$and $\Delta\left[\mathrm{M}^{+}\right]$.
For the sake of simplicity we may suppose that the thermosphere is isothermal and neutral species [O] and $[\mathrm{M}] \approx$ $\left[\mathrm{N}_{2}\right]$ follow the barometric law: [O] $=[0] \exp (-z / H)$ and $[\mathrm{M}]=[\mathrm{M}]_{0} \exp (-1.75 z / H)$, where $H=k T n / \mathrm{mg}$ is the atomic oxygen scale height. The $\mathrm{O}^{+}$production rate may be written as $q\left(\mathrm{O}^{+}\right)=j_{o}[\mathrm{O}] \exp \left(-a C h_{\chi}\right)$, where $j$ is the ionization efficiency depending on the incident solar EUV flux and ionization cross sections, $C h_{\chi}$ is the Chapman function for solar zenith angle $\chi$, and $a$ includes the column density of neutrals multiplied by absorption cross sections. The linear loss coefficient $\beta$ may be written as $\beta=\gamma[\mathrm{M}]$. In this case $\left[\mathrm{O}^{+}\right]=q\left(\mathrm{O}^{+}\right) / \beta \propto \exp (0.75 z / H)$. This is an increasing function with height. The $\mathrm{M}^{+}$-ion concentration following the total ion production rate (Fig. 5) exhibits small height variations in the F1-region passing via the extreme (Figs. 3 and 4$)$. Therefore, $\left[\mathrm{O}^{+}\right]$begins to dominate over $\left[\mathrm{M}^{+}\right]$in the upper part of the F1-region and above in the F2-region. Usually, $\Delta\left[\mathrm{O}^{+}\right]$controls the sign of the F1-layer storm effect (Table 5), and this explains the direct and significant correla- 

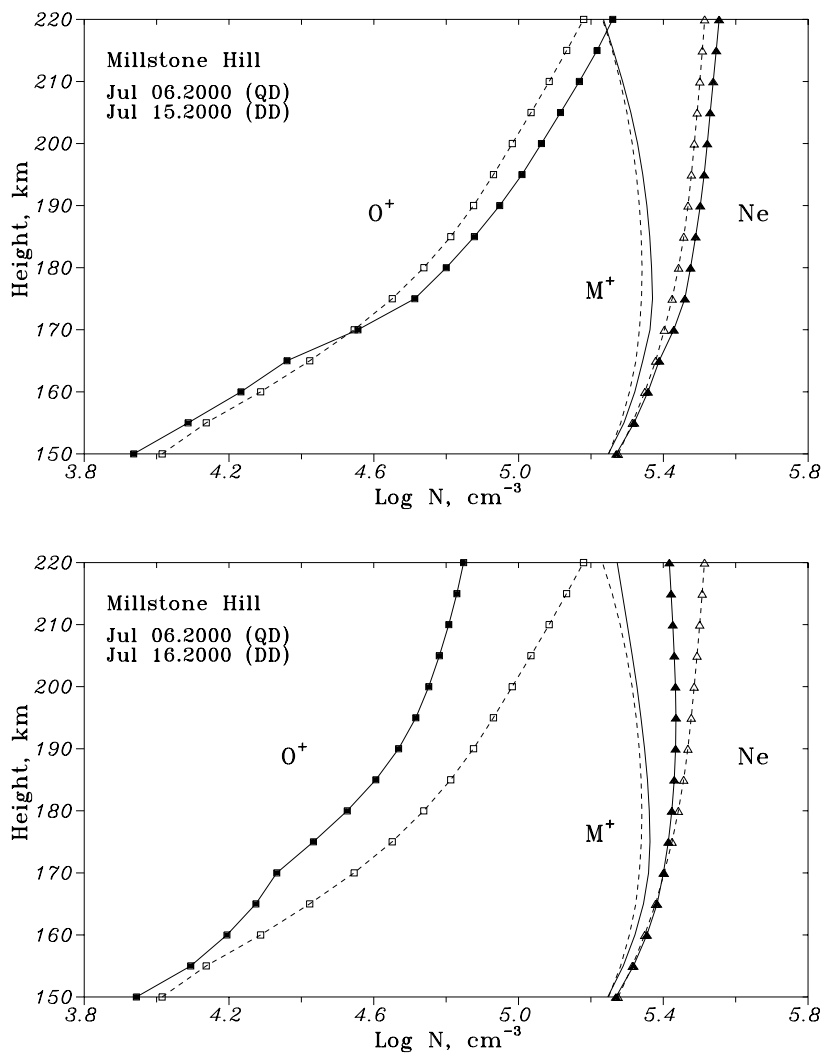

Fig. 6. Same as Fig. 3, but for a very severe geomagnetic storm on 15-16 July 2000.

tion between $\delta N e$ and $\delta N m \mathrm{~F} 2$ (Table 3).

A smaller sensitivity of the F1-region to geomagnetic disturbances compared to the F2-layer usually mentioned in literature is also explained in the framework of this mechanism. In "winter" there is a partial compensation and in "summer" a practically complete compensation of negative $\Delta\left[\mathrm{O}^{+}\right]$by positive $\Delta\left[\mathrm{M}^{+}\right]$, while the pure $\Delta\left[\mathrm{O}^{+}\right]$effect takes place in the F2-region.

\subsection{The 15-16 July 2000 severe storm effect}

This was a very severe geomagnetic storm with a wellpronounced onset on the afternoon of 15 July and a main phase with $D_{s t}$ decreasing down to $-300 \mathrm{nT}$ at 21:00 UT. But it should be noted that the geomagnetic field was also disturbed for the two previous days with $A_{p}=42$ on 13 July and $A_{p}=51$ on 14 July. A strong positive storm effect took place in the F2-region on 15 July which extended down to F1-layer heights (Table 1 and Fig. 2, bottom). On the next day, 16 July there was a complete disappearance of the F2layer at usual heights and a maximum in the $\mathrm{Ne}(h)$ profile in the F1-layer - the so-called G-condition. Despite such severe F2-layer storm effects, implying very strong perturbations in the thermospheric parameters, rather small storm effects were registered at F1-layer heights (Table 1). This effect was also mentioned by Buresova et al. (2002) on the European ionosondes data analysis. The most interesting ques-

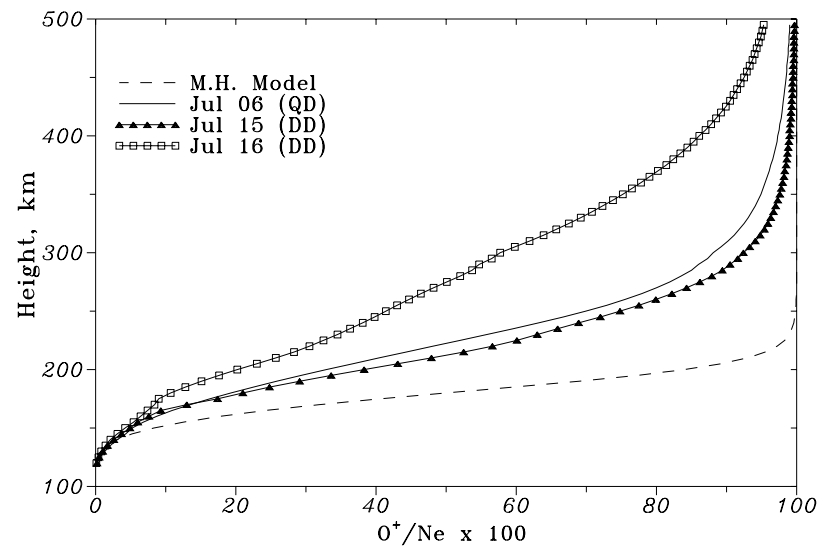

Fig. 7. Calculated $\mathrm{O}^{+} / \mathrm{Ne}$ ratio for the $15-16$ July 2000 storm compared to the Millstone Hill model. Note that the quiet time ion composition also strongly differs from the model one.

tions related to this period are, why is the F1-layer storm effect relatively small on 16 July, and what is the reason for the positive effect on 15 July? Our method was applied to the two disturbed days, 15-16 July, and to a quiet reference day on 6 July. The observations were provided by Millstone Hill IS facility.

Figure 6 shows the calculated $\left[\mathrm{O}^{+}\right],\left[\mathrm{M}^{+}\right]$distributions and their sum for quiet and disturbed days. The first surprising result concerns the reference day. Although 6 July 2000 and the eight previous days were magnetically quiet, the calculated ion composition $\left(\mathrm{O}^{+} / \mathrm{Ne}\right.$ ratio) differs strongly from the model one (Oliver, 1975) used at Millstone Hill for incoherent scatter data analysis (Fig. 7, dashes). This model presents the quiet-time ion composition which is independent of geophysical conditions, while the calculated $\mathrm{O}^{+} / \mathrm{Ne}$ ratio for 6 July corresponds to a disturbed ionosphere enriched strongly with molecular ions. The peculiarity of 6 July also confirms a comparison with the monthly median IRI90 model (Bilitza, 1990) which corresponds to a quiet ionosphere. The IRI-90 gives $N m \mathrm{~F} 2=6 \times 10^{5} \mathrm{~cm}^{-3}$ for the conditions in question, while the observed value is $4 \times 10^{5} \mathrm{~cm}^{-3}$. A comparison of Fig. 6 with Fig. 3 for the 13/5 June 1990 period shows a strong depletion in $\left[\mathrm{O}^{+}\right]$on 6 July 2000 , similar to the disturbed day of 13 June 1990. All this indicates that the reference day of 6 July 2000 is not a typical summer one. It may be attributed to so-called "low" summer dates (Ivanov-Kholodny et al., 1981) or to a quiet-time F2layer deviation discussed by Mikhailov and Schlegel (2001). In both cases the effect is related to a relatively large thermospheric neutral composition variation during geomagnetically quiet periods. Therefore, rather small F1-layer storm effects on 15-16 July may be related to the peculiarity of the preceding reference period. But, nevertheless, we are considering this interesting period which is discussed in literature (Buresova et al., 2002; Pavlov and Foster, 2001; Basu et al., 2001).

Let us consider the calculated variations of aeronomic parameters for the dates in question (Tables 5 and 6 and Fig. 6). 
The earlier discussed compensation of negative $\Delta\left[\mathrm{O}^{+}\right]$by positive $\Delta\left[\mathrm{M}^{+}\right]$takes place for 16 July (Table 5 ), while a summation of positive $\Delta\left[\mathrm{O}^{+}\right]$and $\Delta\left[\mathrm{M}^{+}\right]$results in a positive storm effect on 15 July (see later). Both effects are due to the neutral composition variations (Table 6) and corresponding changes in $q\left(\mathrm{O}^{+}\right), \beta$ and total $q$. Although the atomic oxygen decrease on 16 July is essential (by 2.2 times), this gives rise to a small effect in $\Delta N e$ (Fig. 6). As mentioned earlier, the initial $\left[\mathrm{O}^{+}\right]$contribution to $N e$ is relatively small compared to the $\left[\mathrm{M}^{+}\right]$one; therefore, an additional decrease in $[\mathrm{O}]$ has practically no effect at F1-layer heights where molecular ions dominate. But this turns out to be crucial for the F2-region, where the normal F2-layer has disappeared (G-condition). This effect was analyzed earlier for Millstone Hill (Mikhailov and Foster, 1997) and EISCAT (Mikhailov and Schlegel, 1998) observations.

\subsection{Positive storm effects}

Our morphological analysis (Tables 1 and 2) has shown some cases of positive F1-layer storm effect with the magnitude both increasing and decreasing with height. Usually, the positive effects are not large but they are considered as well, in order to make the picture complete. The 15 July 2000 case with the height increasing effect (Figs. 2 and 6) is mostly due to the atomic oxygen increase (Table 6). This increase in [O], along with the enhanced vertical plasma drift (due to the storm-induced equatorward thermospheric wind), results in a strong positive effect at the F2-layer heights (Fig. 2). So, this case may be attributed to normal F-layer positive disturbances.

A positive storm effect decreasing with height is presented by the 11/14 January 1990 case (Table 1). The observed $N e(h)$ profiles show a small positive $\Delta N e$ effect in the bottomside which disappears in the vicinity of the F2layer maximum and appears again in the topside. The calculated $\Delta\left[\mathrm{O}^{+}\right]$and $\Delta\left[\mathrm{M}^{+}\right]$variations are shown in Fig. 8 (top). Below $180 \mathrm{~km}$ the summation of both positive $\Delta\left[\mathrm{O}^{+}\right]$ and $\Delta\left[\mathrm{M}^{+}\right]$results in a noticeable positive effect in $N e$. At $180 \mathrm{~km}$ the resultant $\Delta N e$ is totally due to $\Delta\left[\mathrm{O}^{+}\right]$, while above $180 \mathrm{~km} \Delta\left[\mathrm{O}^{+}\right]$and $\Delta\left[\mathrm{M}^{+}\right]$act in opposite directions, decreasing the resultant $\Delta N e$. Although $\Delta\left[\mathrm{O}^{+}\right]$dominates over $\Delta\left[\mathrm{M}^{+}\right]$above $180 \mathrm{~km}$, its magnitude decreases with height and there is no storm effect at $220 \mathrm{~km}$.

The calculated variation of aeronomic parameters is given in Table 6 (bottom line) and the ion production rates are shown in Fig. 8 (bottom). An interesting result is a decrease in concentration of all neutral species for the disturbed day. Despite this decrease in $[\mathrm{O}]$, we have positive $\Delta\left[\mathrm{O}^{+}\right]$, which is mainly due to the $\Delta \beta$ decrease (see Eq. 4). The latter is clearly seen at $180 \mathrm{~km}$, where $\Delta q\left(\mathrm{O}^{+}\right)=0$ (Table 6). Positive $\Delta\left[\mathrm{M}^{+}\right]$below $180 \mathrm{~km}$ is mainly due to the increase in the total ion production rate (Fig. 8, bottom and Eq. 4). All ion production rate profiles are seen to be shifted down by $\approx 20 \mathrm{~km}$ for the disturbed day and this is quite different from the other storm cases considered.
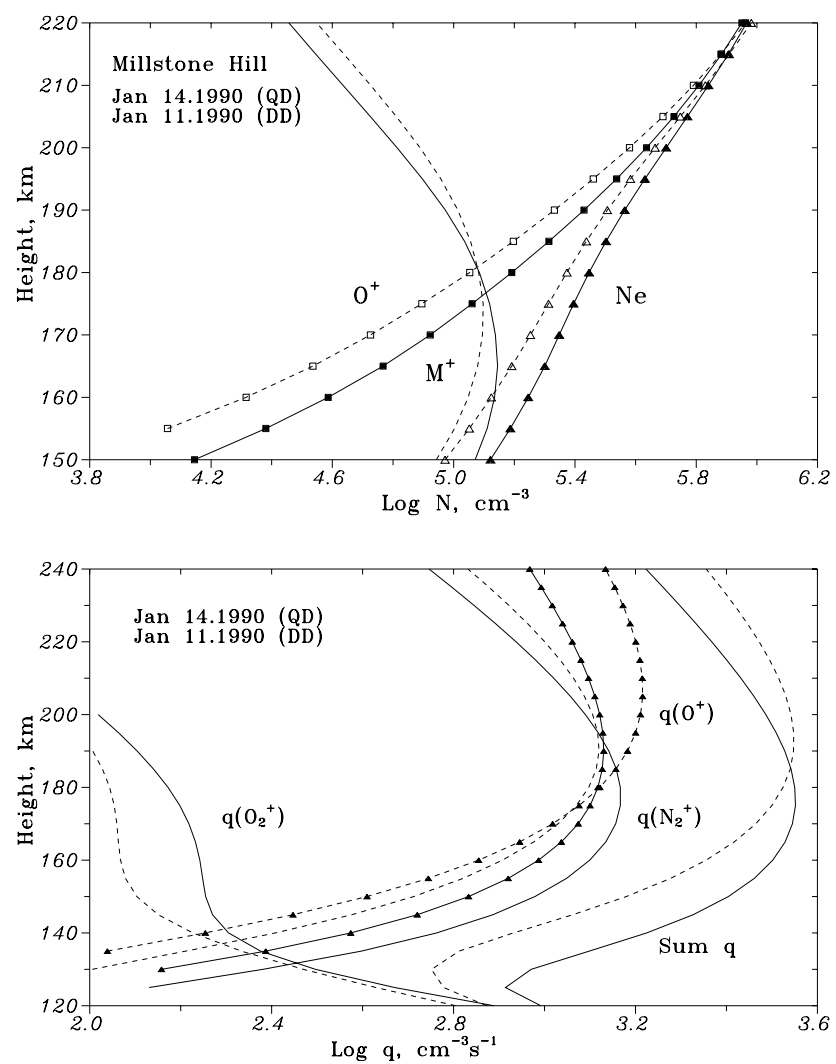

Fig. 8. Same as Fig. 3, but for a positive disturbance on 11 Jan/14 Jan 1990 with a height decreasing storm effect (top) and calculated ion production rates for this case (bottom).

\section{Discussion}

Incoherent scatter observations are known to provide the most complete and consistent information on ionospheric plasma in the F-region. Observed $N e(h)$ profiles were used in the paper for the analysis of the morphology of F1-layer storm effects. Our self-consistent method was successfully used for the physical interpretation of the storm effects. Nevertheless, some problems should be mentioned in relation with the use of IS observations. Unlike ground-based ionosonde data the IS observations are irregular in time and it is not always possible to find a suitable combination of disturbed/quiet days for the analysis; therefore, the usable amount of data is limited. The quality of the experimental material is different at Millstone Hill and EISCAT. Due to rare (usually 3 per hour) observations at Millstone Hill, we had to use a 3-4 h period to calculate median profiles. It is not always possible (especially for disturbed days) to find a 3-4 h period around noon of relative stability in $N m \mathrm{~F} 2$ and $h m \mathrm{~F} 2$ variations. This criterion is applied to decrease the scatter in the observations and increase the reliability of median profiles. Unlike EISCAT observations there is a problem with using the routine $V z(h)$ data at Millstone Hill, as they may need an additional correction due to technical reasons. Therefore, not all available routine Millstone Hill observa- 
tions can be used for our model calculations.

Another well-known general problem with IS observations is related to the ion composition, and this is especially important in case of the F1-layer data analysis. Experimental $T e(h), T i(h)$ and $N e(h)$ profiles derived from the incoherent scatter data analysis depend on the ion composition used in the fit of the theoretical to the measured autocorrelation function (ACF). An uncertainty in ion composition may lead to considerable uncertainties in the derived $T e(h)$ and $T i(h)$ profiles and to somewhat smaller uncertainties in $N e(h)$ (e.g. Waldteufel, 1971; Lathuillère et al., 1983). The effect of varying ion composition is most noticeable during disturbed periods, but an appreciable effect may also take place for quiet periods as well (e.g. 6 July 2000). The largest uncertainties take place at the F1-region heights, where the ion composition changes from molecular to atomic one. Therefore, a correction of the experimental $\mathrm{Te}(h), \mathrm{Ti}(h)$ and $\mathrm{Ne}(h)$ profiles is required. A simple correction proposed by Waldteufel (1971) may be applied when the deviations in ion composition from the model (used in the IS data analysis) are not large, but in the case of strong perturbations, such as those present in the July 2000 event (Fig. 7), this simple correction results in unreal $T e(h)$ and $T i(h)$ profiles. In such cases a more sophisticated iterative method considered by Mikhailov and Schlegel (1997) should be applied, which provides the proper fit to the measured ACF. This iterative method requires considerable calculations and cannot be applied routinely.

EISCAT observations (each particular experiment) are not normalized by $f o \mathrm{~F} 2$ values. Although the declared uncertainty in the measured electron concentration is not large $-10 \div 12 \%$ (Farmer et al., 1984; Kirkwood et al., 1986), this may result in wrong relative deviations $\delta N e$ when different (quiet/disturbed) days are compared. The absence of such normalization also results in a shift between long-pulse and multi-pulse $N e(h)$ profiles, and this shift should be taken into account before the profiles are used for analysis. Unfortunately, $f o \mathrm{~F} 2$ data (due to problems with ground-based ionosonde observations in the auroral zone) are not available in some interesting cases, and one has to use IS observations, as they are without normalization. Despite the problems encountered, the IS observations provide necessary information to specify physical mechanisms of the F1-layer storm effects, and this was implemented using our self-consistent method.

Among the observed storm features at mid-latitudes, the most interesting is a seasonal difference with a less pronounced summer storm effect compared to other seasons. This implies a seasonal difference in the thermosphere reaction to geomagnetic disturbances with the summer $\left[\mathrm{O}_{2}\right]$ and $\left[\mathrm{N}_{2}\right]$ increase, larger than the winter one (see Table 6 for $\Delta \log \left[\mathrm{O}_{2}\right]$ and $\Delta \log \left[\mathrm{N}_{2}\right]$ and Fig. 5 for $\Delta q\left(\mathrm{~N}_{2}^{+}\right)$and $\Delta q\left(\mathrm{O}_{2}^{+}\right)$). The MSIS-86 model (Hedin, 1987) gives very small seasonal differences in $\Delta\left[\mathrm{O}_{2}\right]$ and $\Delta\left[\mathrm{N}_{2}\right]$, even at the F2-region heights $(280 \mathrm{~km})$ and practically negligible $\Delta\left[\mathrm{O}_{2}\right]$ and $\Delta\left[\mathrm{N}_{2}\right]$ variations in the F1-region $(180 \mathrm{~km})$. On the other hand, the ESRO-4 observations (Prölss and von Zahn, 1977) show a seasonal difference in $\Delta\left(\mathrm{N}_{2} / \mathrm{O}\right)$ at $280 \mathrm{~km}$ for middle latitudes and daytime hours (their Fig. 4). According to the model of thermospheric composition by Zuzic et al. (1997) based on the ESRO-4 observations, larger $\mathrm{N}_{2} / \mathrm{O}$ disturbance intensity corresponds to larger $\Delta\left[\mathrm{N}_{2}\right]$ and smaller $\Delta[\mathrm{O}]$, although the latter demonstrates large scatter (their Fig. 6). This seasonal difference in the thermospheric reaction may be attributed to the enhanced Joule heating in summer and to the storm-induced/background thermospheric winds interaction (e.g. Fuller-Rowell and Codrescu, 1996).

Unlike the F2-layer, where the role of dynamical processes (thermospheric winds, in particular) is essential, the electron concentration in the F1-region (heights below $200 \mathrm{~km}$ ) is controlled by photochemical processes. Therefore, the observed $N e F 1$ variations just reflect the variations of neutral composition and temperature. By analogy with the F2-layer (Prölss, 1993), a decrease in the $\mathrm{O} /\left(\mathrm{N}_{2}+\mathrm{O}_{2}\right)$ ratio results in the negative storm effect, while F1-layer positive storm effect may be due to some other mechanisms. In particular, the positive storm effect at F1-layer heights on 15 July 2000 is mostly due to the atomic oxygen increase, as our analysis has shown. The height decreasing positive storm effect on 11 January 1990 (Fig. 8), on the other hand, was shown to be due to a thermosphere contraction below $220 \mathrm{~km}$ which resulted in a decrease of neutral concentrations at a given height (e.g. at $180 \mathrm{~km}$ in Table 6). This decrease in neutral atmosphere density has clearly appeared in the total ion production rate (Fig. 8, bottom). The $q(h)$ profile is shifted down as a whole without change in the maximum production rate. Such type of neutral atmosphere variation may be related to a passage of planetary or gravity waves during disturbed periods (e.g. Burns and Killeen, 1992).

Coming back to the small storm effect on 16 July 2000 related to the peculiarity of the reference day 6 July, an additional argument may be mentioned. The calculated total neutral density is $\rho=1.01 \times 10^{-11} \mathrm{~g} \mathrm{~cm}^{-3}$ at $180 \mathrm{~km}$, and this is twice as much as on 5 June 1990, although the geophysical conditions were close for the two days. For the disturbed day 13 June 1990 the neutral density $\rho$ has increased by a factor of 1.6 while, $\rho$ has turned out to be practically unchanged on 16 July 2000 with respect to the reference day of 6 July 2000 . Since neutral density at $180 \mathrm{~km}$ is mainly represented by molecular nitrogen $\mathrm{N}_{2}$, such a stability in $\rho$ may be an indication of a "saturation" of the lower thermosphere with molecular species. With more or less a fixed concentration of $\mathrm{N}_{2}$ at the turbopause level and similar temperatures, one should have similar $\left[\mathrm{N}_{2}\right]$ values. Indeed, the neutral temperatures (calculated at $180 \mathrm{~km}$ ) are similar $-1158 \mathrm{~K}$ on 6 July and $1161 \mathrm{~K}$ on $16 \mathrm{July}$, and this resulted in similar $\mathrm{N}_{2}$ and $\mathrm{O}_{2}$ concentrations for the two days. Since $\mathrm{Ne}$ reflects mainly molecular ions (see Fig. 6, bottom), we have a small storm effect at F1-layer heights on 16 July 2000. 


\section{Conclusions}

Our morphological analysis of the storm effects at F1-layer heights (160-200 km) using EISCAT and Millstone Hill incoherent scatter observations followed by physical interpretation has shown the following.

The morphological results:

1. The storm effects in $\mathrm{Ne}$ may be positive and negative, but negative deviations prevail for all seasons. The magnitude of the positive effect is smaller compared to the negative one.

2. Usually, the amplitude of deviation increases with height, but the inverse type of dependence may also take place.

3. There is a direct and significant correlation between $\delta N e$ at the F1-layer heights and $\delta N m \mathrm{~F} 2$, the correlation coefficients increasing with height.

4. At middle latitudes the summer storm effect is less compared to other seasons, but it is well detectable. In the auroral zone this summer effect takes place only with respect to the autumnal period, while a spring/autumn asymmetry in the storm effect is well pronounced.

5. The F1-region exhibits a relatively small reaction to geomagnetic disturbances despite large storm perturbations in the thermospheric parameters at the heights in question.

As the F1-region is formed, where both atomic $\mathrm{O}^{+}$and molecular $\mathrm{M}^{+}=\mathrm{O}_{2}^{+}+\mathrm{NO}^{+}$ions strongly contribute to electron concentration $\mathrm{Ne}$, the competition between $\Delta\left[\mathrm{O}^{+}\right]$ and $\Delta\left[\mathrm{M}^{+}\right]$contributions explains the main morphological features, in particular:

6. Normally $\left[\mathrm{O}^{+}\right]$decreases while $\left[\mathrm{M}^{+}\right]$always increases in disturbed conditions. The $\left[\mathrm{O}^{+}\right]$decrease usually prevails (especially during equinoxes and in winter) and this determines the negative sign of the storm effect observed in the majority of cases. The summer $\left[\mathrm{M}^{+}\right]$increase is larger compared to the winter one, and the resultant negative storm effect is smaller in summer due to this compensation. The latter is related to seasonal differences in the thermosphere reaction to geomagnetic disturbances, with the summer $\left[\mathrm{O}_{2}\right]$ and $\left[\mathrm{N}_{2}\right]$ increase larger than the winter one. This revealed seasonal effect is confirmed by ESRO-4 neutral composition observations for disturbed conditions.

7. The small sensitivity of the F1-region to geomagnetic disturbances compared to the F2-layer one is also explained in the framework of this mechanism. There is partial compensation (in winter and equinoxes) or practically complete (in summer) compensation of negative $\Delta\left[\mathrm{O}^{+}\right]$by positive $\Delta\left[\mathrm{M}^{+}\right]$at $\mathrm{F} 1$-layer heights, while the pure $\Delta\left[\mathrm{O}^{+}\right]$effect takes place in the F2-region.
8. The concentration of $\mathrm{O}^{+}$ions increases with height, while $\left[\mathrm{M}^{+}\right]$demonstrates small height variations in the F1-region. Therefore, $\left[\mathrm{O}^{+}\right]$begins to dominate over $\left[\mathrm{M}^{+}\right]$in the upper part of the F1-region and above in the F2-region. Usually, $\Delta\left[\mathrm{O}^{+}\right]$controls the sign of the F1layer storm effect, and this explains both the increase of the storm effect with height and the direct (significant) correlation between $\delta N e$ and $\delta N m \mathrm{~F} 2$.

9. Small, positive storm effects also observed in the F1region may result from different reasons. The increase of atomic oxygen abundance results in a positive effect with a height increasing magnitude. A contraction of the lower thermosphere (presumably due to gravity waves) results in a height decreasing positive storm effect.

10. In summary one may conclude that all the observed F1-layer storm effects may be related to seasonal and storm-time variations of neutral composition $\left(\mathrm{O}, \mathrm{O}_{2}\right.$, $\mathrm{N}_{2}$ ). The present day understanding of the F1-region formation mechanisms is sufficient to explain the observed storm effects.

Acknowledgements. The authors thank the Millstone Hill Group of the Massachusetts Institute of Technology, Westford; also the Director and the staff of EISCAT for running the radar and providing the data. The EISCAT Scientific Association is funded by scientific agencies of Finland (SA), France (CNRC), Germany (MPG), Japan (NIPR), Norway (NF), Sweden (NFR), and the United Kingdom (PPARC). A. V. Mikhailov is grateful to the Max-PlanckGesellschaft for a research stipend at the MPAE.

Topical Editor M. Lester thanks C. Huang and another referee for their help in evaluating this paper.

\section{References}

Antonova, L. A. and Ivanov-Kholodny, G. S.: The F1-layer. Conditions for appearance and height, Geomagn. Aeronom., 28, 813816, 1988a.

Antonova, L. A. and Ivanov-Kholodny, G. S.: The F1-layer. Dependence of electron concentration at the layer maximum on heliogeophysical conditions, Geomagn. Aeronom., 28, 817-819, 1988 b.

Banks, P. M. and Kockarts, G.: Aeronomy, Academic Press, New York, London, 1973.

Basu, S., Basu, Su., Groves, K. M., Yeh, H.-C., et al.: Response of the equatorial ionosphere in the South Atlantic region to the great magnetic storm of 15 July 2000, Geophys. Res. Lett., 18, 3577-3580, 2001.

Bilitza, D. (Ed): International Reference Ionosphere IRI-90, URSICOSPAR, Rep. NSSDC/WDC-A Rocket and Satellites, Greenbelt, USA, 1990.

Buonsanto, M. J.: Ionospheric storms - A review, Space Sci. Rev. 88, 563-601, 1999.

Buresova, D. and Lastovicka, J.: Changes in the F1-region electron density during geomagnetic storms at low solar activity, J. Atmos. Solar-Terr. Phys., 63, 537-544, 2001.

Buresova, D., Lastovicka, J., Atadill, D., and Miro, G.: Daytime electron density at the F1-region in Europe during geomagnetic storms, Ann. Geophysicae, 20, 1007-1021, 2002. 
Burns, A. G. and Killeen, T. L.: The equatorial neutral thermospheric response to geomagnetic forcing, Geophys. Res. Lett., 19, 977-980, 1992.

Danilov, A. D. and Lastovicka, J.: Effects of geomagnetic storms on the ionosphere and atmosphere, Int. J. Geomagn. Aeronom., 2, 209-224, 2001.

Farmer, A. D., Lockwood, M., Horne, R. B., Bromage, B. J. I., and Freeman, K. S. C.: Field-perpendicular and field-aligned plasma flows observed by EISCAT during a prolonged period of northward IMF, J. Atmos. Terr. Phys., 46, 473-488, 1984.

Fuller-Rowell, T. J. and Codrescu, M. V.: On the seasonal response of the thermosphere and ionosphere to geomagnetic storms, J. Geophys. Res., 101, 2343-2353, 1996.

Goldberg, R. A. and Blumle, L. J.: Positive composition from a rocket-borne mass-spectrometre, J. Geophys. Res., 75, 133-142, 1970.

Hedin, A. E.: MSIS-86 thermospheric model, J. Geophys. Res., 92, 4649-4662, 1987.

Hierl, P. M., Dotan, I., Seeley, J. V., Van Doran, J. M., Morris, R. and Viggiano, A. A.: Rate coefficients for the reactions of $\mathrm{O}^{+}$ with $N_{2}$ and $O_{2}$ as a function of temperature (300-1800 K), J. Chem. Phys., 106, 9, 3540-3544, 1997.

Hubert, D. and Kinzelin, E.: Atomic and molecular ion temperatures and ion anisotropy in the auroral F-region in the presence of large electric fields, J. Geophys. Res., 97, 1053-1059, 1992.

Ivanov-Kholodny, G. S. and Nikoljsky G. M.: The Sun and the Ionosphere, Nauka, M., 335, in Russian, 1969.

Ivanov-Kholodny, G. S., Mikhailov, A. V., and Ostrovsky, G. I.: Day-to-day change in the summer values of $h m \mathrm{~F} 2$ and $N m \mathrm{~F} 2$ as a reflection of variations in the neutral composition of the upper atmosphere, Geomagn. Aeronom., 21, 615-617, 1981.

Kirkwood, S., Collis, P. N., and Schmidt, W.: Calibration of electron densities for EISCAT UHF radar, J. Atmos. Terr. Phys., 48, 773-775, 1986.

Lathuillère, C., Lejeune, G., and Kofman, W.: Direct measurements of ion composition with EISCAT in the high-latitude F1-region, Radio Sci., 18, 887-893, 1983.

Lathuillère, C. and Brekke, A.: Ion composition in the auroral ionosphere as observed by EISCAT, Ann. Geophysicae, 3, 557-568, 1985.

Mikhailov, A. V.: Ionospheric F2-layer storms, Fisica de la Tierra, 12, 223-262, 2000.

Mikhailov, A. V. and Foster, J. C.: Daytime thermosphere above Millstone Hill during severe geomagnetic storm, J. Geophys. Res., 102, 17,275-17,282, 1997.

Mikhailov, A. V. and Förster, M.: Day-to-day thermosphere parameter variation as deduced from Millstone Hill incoherent scatter radar observations during 16-22 March 1990 magnetic storm period, Ann. Geophysicae, 15, 1429-1438, 1997.

Mikhailov, A. V. and Förster, M.: Some F2-layer effects during the 6-11 January 1997 CEDAR storm period as observed with the Millstone Hill incoherent scatter facility, J. Atmos. Solar-Terr. Phys, 61, 249-261, 1999.

Mikhailov, A. V. and Kofman, W.: An interpretation of ion composition diurnal variation deduced from EISCAT observations, Ann. Geophysicae, 19, 351-358, 2001.

Mikhailov, A. V. and Schlegel, K.: Self-consistent modeling of the daytime electron density profile in the ionospheric F-region, Ann. Geophysicae, 15, 314-326, 1997.

Mikhailov, A. V. and Schlegel, K.: Physical mechanism of strong negative storm effects in the daytime ionospheric F2-region observed with EISCAT, Ann. Geophysicae, 16, 602-608, 1998.
Mikhailov, A. V. and Schlegel, K.: A self-consistent estimate of $\mathrm{O}^{+}+\mathrm{N}_{2}$ rate coefficient and total EUV solar flux with $\lambda 1050 \AA$ using EISCAT observations. Ann. Geophysicae, 18, 1164-1171, 2000 .

Mikhailov, A. V. and Schlegel, K.: Equinoctial transitions in the ionosphere and thermosphere, Ann. Geophysicae, 19, 783-796, 2001.

Nusinov, A. A.: Models for prediction of EUV and X-ray solar radiation based on $10.7 \mathrm{~cm}$ radio emission., Proc. Workshop on Solar Electromagnetic Radiation for Solar Cycle 22, Boulder, Co., July 1992, (Ed) Donnely, R. F., NOAA ERL. Boulder, Co., USA, 354-359, 1992.

Oliver, W. L.: Models of the F1-region ion composition variations, J. Atmos. Terr. Phys., 37, 1065-1076, 1975.

Pavlov, A. V. and Foster, J. C.: Model/data comparison of F-region ionospheric perturbation over Millstone Hill during the severe geomagnetic storm of 15-16 July 2000, J. Geophys. Res., 106, 29 051-29069, 2001.

Pollard, J. H.: A handbook of numerical and statistical techniques, Camb. Univ. Press, 1977.

Prölss, G. W.: On explaining the local time variation of ionospheric storm effects, Ann. Geophysicae, 11, 1-9, 1993.

Prölss, G. W.: Ionospheric F-region storms, in Handbook of Atmospheric Electrodynamics, Vol. 2 (Ed) Volland, CRC Press/Boca Raton, 195-248, 1995.

Prölss, G. W. and von Zahn, U.: Seasonal variations in the latitudinal structure of atmospheric disturbances, J. Geophys. Res., 82, 5629-5632, 1977.

Richards, P. G. and Torr, D. G.: Ratios of photoelectron to EUV ionization rates for aeronomic studies, J. Geophys. Res., 93, 4060 4066, 1988.

Richmond, A. D.: Upper-atmospheric effects of magnetic storms: a brief tutorial, J. Atmos. Solar-Terr. Phys., 62, 1115-1127, 2000.

Shchepkin, L. A.: Some patterns in the vertical distribution of electron and ion concentrations at heights between $130-200 \mathrm{~km}, \mathrm{Ge}-$ omagn. Aeronom., 9, 380-384, 1969.

Shchepkin, L. A., Shuyskaya, Z. I., and Koshelev, V. V.: Estimation of the seasonal variation of the gas concentration at the height of the F1-layer from data on the conditions of its development, Geomagn. Aeronom., 12, 870-872, 1972.

Shchepkin, L. A. and Vinitzky, A. V.: Derivation of the foF1 characteristic from ionograms, Geomagn. Aeronom., 21, 257-258, 1981.

St.-Maurice, J.-P. and Schunk, R. W.: Ion velocity distributions in the high-latitude ionosphere, Rev. Geophys. Space Phys., 17, 99134, 1979.

Torr, M. R., Torr, D. G., Ong, R. A., and Hinteregger, H. E.: Ionozation frequencies for major thermospheric constituents as a function of solar cycle 21, Geophys. Res. Lett., 6, 771-774, 1979.

Vinitzky, A. V., Sukhomazova, G. I., and Shchepkin, L. A.: Relationship between the properties of the ionospheric F2- and F1layers in the day-to-day variations, Geomagn. Aeronom., 22, 707-709, 1982.

Waldteufel, P.: Combined incoherent scatter F1-region observations, J. Geophys. Res., 76, 6995-6999, 1971.

Zevakina, R. A., Goncharova, E. E., Pushkova, G. N., and Yodovich, L. A.: Effect of the ring current on on ionospheric Fregion disturbance, Geomagn. Aeronom., 11, 825-829, 1971.

Zuzic, M., Scherliess, L., and Prölss, G. W.: Latitudinal structure of thermospheric composition perturbations, J. Atmos. Solar-Terr. Phys., 59, 711-724, 1997. 